\title{
EL OCASO DEL LATIFUNDIO GREENE: ILEGALIDAD, POLÍTICA INTERNACIONAL Y AGRARISMO EN LA FRONTERA SONORA-ARIZONA, 1954-1958
}

\author{
Miguel Ángel Grijalva Dávila \\ El Colegio de Sonora
}

Cuando hablamos de agrarismo en Sonora, la mayor parte de la bibliografía existente se concentra en los años de la revolución mexicana y los periodos inmediatos al final de la fase armada. Pocos han sido los trabajos sobre el tema en años posteriores. Ahí destacan las colaboraciones de Adrián Bantjes ${ }^{1}$ y Steven E. Sanderson, ${ }^{2}$ cuyas obras abordan el tema durante el gobierno de Lázaro Cárdenas. O los autores de la Historia General de Sonora, ${ }^{3}$ como Rocío Guadarrama, Ricardo León y Cristina Martínez, quienes se aventuraron a cubrir el tema, aunque de manera breve, en periodos posteriores. La historia del agrarismo en Sonora durante la década de 1950 continúa siendo un campo carente de estudios históricos y por lo tanto de poca

Fecha de recepción: 16 de marzo de 2016

Fecha de aceptación: 5 de abril de 2017

${ }^{1}$ Bantjes, As if Jesus Walked on Earth.

2 Sanderson, Agrarian Populism.

3 Camou Healy, Guadarrama, León, Ramírez, Historia General de Sonora. 
variedad de interpretaciones que inciten al debate historiográfico. Lo mismo podemos decir para todo el noroeste mexicano.

Por lo anterior, este artículo abre un diálogo no con historiadores, sino con los autores que más han escrito sobre el tema: aquellos que lo vivieron. Al revisar los textos sobre el agrarismo en Sonora durante el cardenismo y décadas posteriores, encontramos una carencia de trabajos históricos y una abundancia de textos escritos por los protagonistas de los hechos. Así el caso de Humberto Ochoa, ${ }^{4}$ líder campesino; Alejandro Olais, ${ }^{5}$ Luis Encinas Johnson, ${ }^{6}$ Ángel López ${ }^{7}$ y José Abraham Mendívil, ${ }^{8}$ políticos locales; Erasmo Lozano, ${ }^{9}$ abogado, y Carlos Moncada, ${ }^{10}$ periodista.

Las expropiaciones en el norte de Sonora durante 1958, caso que exploramos en este artículo, han despertado poco interés por parte de los historiadores del agrarismo, pues resultan un caso extraño por las siguientes características: 1 ) se trataba de un latifundio cuyas tierras no se usaban para el cultivo y sus propietarios no eran agricultores; 2) aunque era ampliamente sabido que se trataba del latifundio más grande de la entidad, los gobiernos de la revolución mexicana no le prestaron atención a los reclamos de expropiación; 3) las compañías que controlaban el latifundio eran estadounidenses, pero curiosamente el gobierno de dicho país no se opuso a la expropiación, incluso la alentó; 4) aunque fue expropiado y repartido entre centrales campesinas, jamás se destinó a la agricultura.

\footnotetext{
${ }^{4}$ Ochoa, Biografía.

${ }^{5}$ Olais, Sonora reta al sistema.

${ }^{6}$ Encinas, Progreso.

7 López, Encuentro con mi destino.

${ }^{8}$ Mendívil, Cuarenta años; Don Ignacio Soto; La democracia en Sonora; Mi duelo a muerte; PAN contra PRI.

${ }^{9}$ Lozano, Remembranzas.

10 Moncada, Cincuenta años en esto; Diez en el poder; Dos siglos de periodismo; La sucesión politica en Sonora.
} 
Esas extrañas características produjeron las preguntas que guiaron nuestra indagatoria: si realmente era la propiedad más grande de la entidad, ¿’por qué su expropiación se retrasó tanto respecto a las expropiaciones del movimiento revolucionario? ¿Cómo fue posible que compañías estadounidenses mantuvieran el control de las tierras? ¿Cómo influyó la postura del gobierno estadounidense en el acto de expropiación y reparto?

El proyecto Coronado Park fue planteado por el gobierno de Estados Unidos desde la década de 1930 e implicaba la creación de un parque transfronterizo, es decir, una reserva forestal que tuviera entrada y salida por ambos lados de la frontera SonoraArizona. Varios eran los obstáculos para la creación de este proyecto, pero el principal era una inmensa propiedad privada al norte de Sonora, un terreno que no pertenecía a la nación, sino a un grupo de sociedades anónimas que funcionaban como prestanombres para una compañía ganadera estadounidense. Esta enorme propiedad privada, hasta entonces la más grande en la entidad, era conocida como el latifundio de Cananea, por encontrarse en las inmediaciones de esta ciudad, o latifundio Greene, por el apellido de la familia que la tenía bajo su control.

El latifundio Greene evadió a la ley mexicana por décadas. La ilegalidad de la propiedad era bien conocida por los campesinos peticionarios, pero ésta no era la única razón por la cual muchos sonorenses deseaban su expropiación. Había un peso simbólico en aquella propiedad, la cual, por cierto, se localizaba en una zona montañosa, rodeada de serranías y que se había caracterizado por su riqueza en minerales, no en cultivos.

El factor simbólico por el cual muchos sonorenses deseaban la expropiación del latifundio, era que estaba controlado por los descendientes del empresario William Cornell Greene, apodado 
por el New York Times como "The American Copper King"11 (El rey americano del cobre) y definido por el historiador Héctor Aguilar Camín como "un arquetipo humano de la historia del capitalismo y del oeste de los Estados Unidos". ${ }^{12}$ Greene era como Edward Doheny (magnate petrolero), pero buscó su riqueza en el oro cobrizo, no en el oro negro.

\section{III}

William Greene nació en Duck Creek, Wisconsin, a mediados del siglo XIX; creció en una familia de cuáqueros y fue educado en escuelas privadas de Nueva York. El dinamismo del oeste de Estados Unidos, el descubrimiento de minas y la creación de nuevas poblaciones le ofreció aventura, riesgos y la posibilidad de enriquecerse. Se estableció en Tombstone, Arizona, en la década de 1870, y trabajó como empleado ferrocarrilero. Luego se trasladó con su familia a Huachuca, en el mismo estado, para dedicarse a la ganadería y la minería. ${ }^{13}$

Ahí tuvo disputas con uno de sus vecinos, el señor James C. Burnett, quien para abastecerse de agua destruyó una presa que había construido William Greene. Lo anterior ocasionó que cambiara la profundidad de un río donde se bañaban los hijos de Greene. Un día, una de las hijas Greene fue a bañarse sin saber que había aumentado la profundidad del río y, peor aún, sin saber nadar. Se arrojó al agua y murió ahogada. ${ }^{14}$ La familia

${ }_{11}$ Terry Greene, "Grandfather figure” [en línea], Arizona Highways (jul. 2013), www.regionalmagazines.org/downloads/competition/AHM-2013ctgy06-Gen-Fea.pdf. Consulta: abril de 2015.

12 Gracida, "El Sonora moderno", p. 88.

13 Terry Greene, "Grandfather figure" [en línea], Arizona Highways (jul. 2013), regionalmagazines.org/downloads/competition/AHM-2013-ctgy06Gen-Fea.pdf. Consulta: abril de 2015.

${ }^{14}$ C. Fahey, "Col. William Cornell Greene" [en línea], Irish Nerwspapers (7 jun. 2007, http://www.findagrave.com/cgi-bin/fg.cgi?page=gr\&GRid= 19768190 . Consulta: marzo de 2015. 
aprendió que el oeste no sólo ofrecía posibilidades de riqueza y aventura, sino también amarguras y peligros. William Greene se vengó y asesinó a balazos a Burnett. Se entregó a los comisarios locales, quienes eran sus amigos y compartían su disgusto por Burnett, y después de alegar defensa propia fue absuelto del crimen. ${ }^{15}$

Poco después Greene adquirió un rancho en la frontera con Sonora y descubrió grandes yacimientos de cobre en la región de Cananea. El gobierno de Porfirio Díaz le dio la concesión para explotar los yacimientos y fundó la Cananea Consolidated Copper Company (CcCC). La llegada de Greene a Sonora coincidió con una ola de inversionistas extranjeros, sobre todo estadounidenses, quienes fueron atraídos por el gobierno del general Díaz. Greene se enriqueció y con él creció Cananea. Hablar de la creación de esta ciudad es hablar de la CcCC y de William Greene. La localidad contaba con 1000 pobladores en 1900, cuando Greene inició el desarrollo de su emporio. Con él llegaron el ferrocarril, la modernidad en maquinarias para la mina, migrantes en busca de trabajo, población cosmopolita proveniente de Estados Unidos y Asía, y un cambio en todos los aspectos de la vida social. Después de cinco años Cananea contaba con alrededor de 20000 pobladores. ${ }^{16}$

La histórica huelga de Cananea de 1906 fue el inicio del declive del emporio de William Greene. Como propietario de "las cuatro C" (apodo con que los mexicanos se referían a la CCCC), a los ojos de muchos fue el responsable de las injusticias que sufrían los mineros mexicanos. Además de reclamar mejoras salariales y una reducción en la jornada laboral, los líderes de la

${ }^{15}$ C. Fahey, "Col. William Cornell Greene” [en línea], Irish Nerwspapers (7 jun. 2007), http://www.findagrave.com/cgi-bin/fg.cgi?page=gr\&GRid= 19768190 . Consulta: marzo de 2015.

${ }^{16}$ C. Fahey, "Col. William Cornell Greene” [en línea], Irish Newspapers (7 jun. 2007), http://www.findagrave.com/cgi-bin/fg.cgi?page=gr\&GRid= 19768190 , p. 93. Consulta: marzo de 2015. 
huelga pidieron igualdad de pago y trato con los trabajadores de origen estadounidense, quienes recibían mejores sueldos y eran los únicos con derecho a ser ascendidos. Fue por esto que la huelga tomó un fuerte peso simbólico y se consideró a Greene como enemigo del nacionalismo mexicano.

El magnate, para entonces ya conocido como el rey americano del cobre, intentó evitar el conflicto, habló con los líderes obreros y les recordó que él había sido minero, que conocía el trabajo duro que realizaban los mexicanos pero que no podía subirle el sueldo, pues esto haría que la empresa no fuera redituable. También señaló que los sueldos que pagaba la cccc eran mejores que los de cualquier otra mina en México. En cuanto a quién recibía ascensos y quién no, Greene explicó que como propietario de la mina era su derecho decidir, según sus criterios, fueran cuales fueran, quiénes eran dignos de ascenso. ${ }^{17}$

Los sindicalistas no escucharon excusas y estalló la huelga en junio de 1906. La situación se salió de control en la maderería, donde trabajadores estadounidenses recibieron a los huelguistas con chorros de agua. Aquello desembocó en enfrentamientos violentos por toda la ciudad y se propagaron noticias sobre el caos que azotaba a Cananea. William Green le envió telegramas al gobernador Rafael Izabal para pedirle su auxilio, quien a su vez movilizó a elementos de la zona militar y permitió que entrara a México un cuerpo de rangers provenientes de Arizona. Las fuerzas llegaron a la ciudad de noche, cuando la situación ya se encontraba tranquila. El saldo del conflicto fue de más de dos decenas de muertos, la mayoría mexicanos. ${ }^{18}$

En aquella coyuntura, Rafael Izabal perdió popularidad y legitimidad por defender a los estadounidenses y permitir la entrada de tropas foráneas a México. La huelga se convirtió en un símbolo de la política antiobrerista del porfiriato y William

17 CÁrdenas, "La huelga de Cananea”, p. 133.

18 Gracida, "El Sonora moderno”, pp. 122-123. 
Greene fue repudiado por obreros e intelectuales. Así lo constataron algunos líderes de la huelga, como Esteban Baca Calderón ${ }^{19}$ y Lázaro Gutiérrez de Lara, quien huyó a Estados Unidos y regresó como intérprete del periodista John Kenneth Turner, autor del libro antiporfirista México bárbaro, ${ }^{20}$ que dedica uno de sus capítulos a la huelga de Cananea.

El imperio minero de William Greene sufrió grandes pérdidas luego del conflicto laboral. Las noticias sobre la violencia desatada en Cananea provocaron que muchos inversionistas de la compañía retiraran sus acciones y en una jornada de labores en Wall Street la riqueza de Greene se redujo de 50 a 14000000 de dólares. ${ }^{21}$ La caída en el precio del cobre vino a rematar el imperio de Greene, quien se vio obligado a vender la cccc.

El rey americano del cobre terminó derrotado, financiera y emocionalmente. Desarrolló una condición cardiaca adversa y entró en depresión. De la noche a la mañana se desvanecieron su emporio y su sueño. Tomó un barco y viajó a Japón, lugar que siempre anheló conocer. ${ }^{22} \mathrm{~A}$ su regreso, contra el consejo de familiares y amigos, se reinstaló en su hogar en Cananea, desde donde, mientras tomaba el café de la mañana, admiraba la mina por la cual trabajó, luchó y perdió.

Mantuvo sus tierras, ranchos y caballerizas, lugares donde pasaba la mayor parte del tiempo. A diferencia de otros empresarios del porfiriato, se negó a abandonar México al estallar la Revolución. Planeaba recuperar la riqueza perdida con la construcción de varias presas, pero se le atravesó la muerte. Se cayó

\footnotetext{
${ }^{19}$ BACA, Juicio sobre la guerra Yaqui.

20 TuRner, México bárbaro.

${ }^{21}$ Terry Greene, "Grandfather figure" [en línea], Arizona Highways (jul. 2013), regionalmagazines.org/downloads/competition/AHM-2013-ctgy06Gen-Fea.pdf. Consulta: abril de 2015.

${ }^{22}$ Terry Greene, "Grandfather figure" [en línea], Arizona Highways (jul. 2013), regionalmagazines.org/downloads/competition/AHM-2013-ctgy06Gen-Fea.pdf. Consulta: abril de 2015.
} 
de una carreta y se quebró tres costillas y una clavícula. También, consecuencia de su mermada salud, adquirió una neumonía que le dio muerte una mañana de septiembre de 1911. Fue sepultado en California. ${ }^{23}$ Heredó sólo unos cuantos cientos de dólares a sus hijos, pues había puesto a nombre de su esposa sus propiedades y compañías ganaderas: ${ }^{24}$ la Cananea Cattle Company y la Greene Cattle Company. Ambas siguieron en operación en la enorme propiedad que adquirió Greene al norte de Sonora, identificada desde entonces como el latifundio Greene, el más grande del estado.

Su familia siguió poseyendo las tierras. Varios líderes de la huelga de 1906 adquirieron autoridad e influencia con el movimiento revolucionario, por ejemplo Manuel M. Diéguez y Esteban Baca Calderón, quienes obtuvieron el grado de general. Pero ninguno se empeñó en expropiar a los herederos de William Greene. Jacinto López Moreno, quien nació el mismo año de la huelga de Cananea, se mudó a esta ciudad minera a mediados de la década de 1920 (era originario de Banámichi) y durante su estancia en el mineral se relacionó con los trabajadores mineros, campesinos, gambusinos, leñadores y ganaderos. Notó que aún existían abismales diferencias en las condiciones de vida de los ciudadanos mexicanos y estadounidenses, y que el apellido Greene controlaba la vida de la región, explotaba a los trabajadores y reprimía a los gambusinos o leñadores que se atrevieran a pisar sus tierras. Las autoridades de Cananea arrestaron a Jacinto López por organizar uniones para reclamar la expropiación de las tierras. Lo trasladaron a Hermosillo contra su voluntad, amenazado de no regresar al mineral. ${ }^{25}$

${ }^{23}$ C. Fahey, "Col. William Cornell Greene” [en línea], Irish Newspapers (7 jun. 2007), http://www.findagrave.com/cgi-bin/fg.cgi?page=gr\&GRid= 19768190 . Consulta: marzo de 2015.

${ }^{24}$ Terry Greene, "Grandfather figure" [en línea], Arizona Highways (jul. 2013), regionalmagazines.org/downloads/competition/AHM-2013-ctgy06Gen-Fea.pdf. Consulta: abril de 2015.

${ }^{25}$ Grijalva, “Jacinto López Moreno”, p. 35. 
Desde ese entonces, Jacinto López y otros líderes, como el profesor Ramón Oquita Montenegro, ${ }^{26}$ reclamaron la expropiación del latifundio Greene. Pero con aliados en el gobierno y estrategias para evadir la ley, la familia Greene siguió en posesión del latifundio. Las presiones fueron cada vez más fuertes e hicieron que fuera inminente la expropiación o al menos la venta forzada de las tierras. Aun así, William Greene Jr. trasladó los restos de su padre a Cananea en $1955,{ }^{27}$ tan sólo tres años antes de que las tierras fueran invadidas y expropiadas. Ahí descansa el rey americano del cobre, en la tierra donde buscó, encontró y perdió su sueño. En el panteón su tumba se localiza fácilmente, pues es una lápida rectangular, sencilla y con inscripciones discretas (muy al estilo de los miembros de las iglesias protestantes), rodeada de tumbas católicas de ornamentaciones vistosas.

El latifundio Greene sobrevivió a las expropiaciones de la revolución mexicana, en gran medida porque estaba formado por terrenos poco propicios para la agricultura. Cuando se le propuso la expropiación al presidente Lázaro Cárdenas del Río, se negó con el argumento de que eran tierras de poca utilidad para los campesinos ${ }^{28}$ grupo al cual él intentaba beneficiar con las expropiaciones de su sexenio. Varios factores ayudan a explicar por qué, a pesar de la oposición de importantes personajes, como por ejemplo el expresidente Emilio Portes Gil, ${ }^{29} \mathrm{el}$

\footnotetext{
${ }^{26}$ Sindicalista nacido en Arivechi, Sonora, de formación normalista. Se estableció en Cananea, donde organizó a trabajadores y campesinos. Dedicó los últimos años de su vida a reclamar la expropiación del latifundio Greene.

${ }_{27}$ Terry Greene, "Grandfather figure" [en línea], Arizona Highways (julio de 2013), regionalmagazines.org/downloads/competition/AHM-2013-ctgy06Gen-Fea.pdf. Consulta: abril de 2015.

28 "Mexico. Last of the latifundios", Time, 9, Lxxi (sep. 1958), p. 28.

${ }^{29}$ Durante una entrevista con el diario Excelsior (14 y 15 mayo 1975), Gilberto Flores Muñoz confesó que el expresidente Emilio Portes Gil
} 
gobierno determinó expropiar el latifundio en 1958. Una razón determinante fueron las declaraciones de Rosina Cavazos y la labor de su abogado, Erasmo Lozano Rocha, quienes redactaron informes detallados sobre el latifundio, su conformación y las maneras como violaba las leyes mexicanas.

De los hijos de William Cornell Greene, el que tuvo más relevancia en los asuntos del latifundio fue el que heredó su nombre, William Greene Jr., mejor conocido como Billy Greene. Este personaje se volvió el rostro del latifundio, pues era el único que hablaba español, visitaba constantemente Cananea (el resto de los propietarios rara vez cruzaba la frontera), y era el único casado con una mujer de nacionalidad mexicana, ${ }^{30}$ Rosina Cavazos de Greene. Poco conocemos de la relación de Billy Greene y Rosina Cavazos, pero algo es seguro: no fue un matrimonio exitoso, pues terminaron divorciándose. Ignoramos las razones de la separación, pero todo apunta a que la ruptura no fue en buenos términos, pues el abogado de Rosina Cavazos no sólo la representó en el caso del divorcio, también la ayudó a hacer públicas las formas ilegales mediante las cuales la familia Greene mantenía el control del latifundio. Esta información llegó a los diarios y a la presidencia en 1954.

Como se mencionó, era ampliamente conocida la ilegalidad del latifundio Greene, pero a los campesinos peticionarios les resultaba difícil comprobarla. Las declaraciones de Rosina Cavazos pusieron en aprietos a los Greene, pues ya no eran acusados por personajes ajenos a ellos, sino por un miembro de su propia familia. El gobierno se vio más presionado que antes, pues los reclamos de expropiación ahora venían acompañados con las pruebas que aportó Rosina Cavazos. Su abogado, Erasmo Lozano Rocha, les expuso a la prensa y autoridades

fungió como defensor de los propietarios del latifundio. LeñEro, Asesinato, pp. 81-82.

${ }_{30}$ Entrevista al exgobernador Álvaro Obregón Tapia, realizada por Nicolás Pineda Pablos, Hermosillo, 7 de diciembre de 1992. 
mexicanas que el terreno conocido como el latifundio Greene era una enorme propiedad en manos de un mismo grupo, pero que legalmente aparentaba estar bajo el control de distintas compañías. Según Lozano Rocha, los propietarios del terreno en cuestión cometían tres violaciones a la ley mexicana:

1) Violación al artículo 27 constitucional con el conglomerado de terrenos conocido como latifundio Greene y unas residencias en la ciudad de Cananea. Las propiedades estaban dentro de los últimos cien kilómetros del territorio mexicano, franja territorial donde la Constitución mexicana prohibía que los extranjeros fueran propietarios.

2) Violación a las leyes migratorias, fiscales, de vías generales de comunicación, aduanales y bancarias, todas perpetradas por el férreo control que tenían los propietarios de los terrenos en cuestión.

3) Violación a las regulaciones de constitución y creación de empresas, pues las empresas de los Greene se constituyeron sin el permiso de la Secretaría de Relaciones Exteriores. Este requerimiento existía desde el 27 de septiembre de 1947 y estipulaba que los notarios públicos no deberían "por ningún motivo autorizar escrituras de constitución de sociedades, cualquiera que sea su índole u objeto, si esta Secretaría [de Relaciones Exteriores] no ha otorgado previamente el permiso". 31

Lozano Rocha responsabilizó en primera instancia a Billy Greene y a su madre Mary Greene Wiswall. En segunda instancia, a todos los propietarios de las compañías Ranchos de Cananea, Productos de Cananea, Ganadera de Cananea, Banco de Cananea, entre otras, todas creadas por los mismos accionistas. Las empresas mencionadas derivaban de la Cananea Realty Company, creada en 1902 por William Cornell Green. Desde que se promulgó la Constitución de 1917, quedó prohibido

${ }^{31}$ Carta del Lic. Erasmo Lozano Rocha al presidente Ruiz Cortines, AGN, Ruiz Cortines, exp. 562.11/8. 
a los extranjeros poseer tierras dentro de una franja de $100 \mathrm{~km}$ antes del límite nacional terrenal y marítimo. A los extranjeros con propiedades en esa condición se les dio un año de plazo para que lo informaran al gobierno mexicano. Aquellas propiedades que no fueran declaradas serían consideradas como creadas después de 1917 y, por lo tanto, serían ilegales. Según Lozano Rocha, la Cananea Realty Company nunca informó que sus propiedades estaban en esta situación y continuó sus labores hasta la década de 1940.

La empresa vendió sus terrenos en 1944 y los compradores fueron pequeñas sociedades anónimas constituidas por mexicanos. Ese mismo año la Cananea Realty Company desapareció. En apariencia, los terrenos dejaron de pertenecer a extranjeros, pero el informe de Lozano Rocha de 1954 negaba esto y aportaba como pruebas varios documentos, entre ellos la correspondencia de Billy Greene (posiblemente tomada por su exesposa Rosina Cavazos). Una carta de particular importancia develaba los planes de Billy Greene y Charles Wiswall para mantener el control de las tierras del latifundio. Charles Wiswall era un personaje clave en el emporio de William Cornell Greene, pues era su hombre de mayor confianza, administrador de sus empresas ganaderas, y después de muerto William Cornell Greene, Wiswall se casó con Mary Greene, viuda de William Cornell. Por lo anterior, Charles Wiswall no sólo era socio de Billy Greene, también era su padrastro.

A principios de diciembre de 1944, Charles Wiswall le avisó a Billy Greene que todos los herederos de William Cornell Greene debían estar en Cananea en diciembre de ese año. El propósito era desintegrar la compañía Cananea Realty Company y crear, entre otras, la Greene Cattle Company y Ranchos de Cananea. Según Wiswall, la maniobra traería varios beneficios: las nuevas compañías no serían propietarias de terrenos, sino arrendatarias, con lo que dejarían de violar el artículo 27 constitucional y evitarían la expropiación, tendrían un mejor 
manejo de los impuestos y con la acción se librarían de muchas deudas. ${ }^{32}$

Dos de las compañías creadas, la Greene Cattle Company y sobre todo Ranchos de Cananea, inmediatamente celebraron contratos de arrendamiento con las pequeñas compañías que compraron las tierras de la Cananea Realty Company. ${ }^{33}$ Según Rosina Cavazos, las nuevas compañías no eran otra cosa que una continuidad de la desaparecida Cananea Realty Company. Los Greene mantuvieron el control de las tierras, las cuales no sólo estaban en la franja de los $100 \mathrm{~km}$ antes de la frontera, sino que incluso se conectaban con las propiedades de los Greene en Arizona. Así, las empresas pasaban ganado de un país a otro sin control aduanero, ${ }^{34}$ razón por lo que Lozano Rocha señaló que violaban las leyes migratorias, fiscales y aduanales.

Ranchos de Cananea era la empresa que tenía arrendada la mayor cantidad de tierras. Poseía contratos de alquiler con 28 compañías cuyas propiedades sumaban 209338 ha, pero individualmente ninguna de esas compañías tenía más de 10000. Además del testimonio de Rosina Cavazos, tres pruebas revelaban que los socios de estas compañías eran prestanombres. La primera era que las tierras se arrendaban al ridículo precio de 3 pesos la ha por año. La segunda era que el pago nunca se realizaba y las empresas nunca lo exigían. Por último, estaba el hecho de que el licenciado Emilio Segura Jr., de nacionalidad mexicana, era el propietario de las 28 compañías arrendadas y, cínicamente, también era el representante legal de Ranchos de Cananea, la compañía que las alquilaba.

32 Carta de las oficinas de la Greene Cattle Company Incorporated, oficina de Los Ángeles, escrita por Charles E. Wiswall, diciembre de 1944, AGN, Adolfo Ruiz Cortines, exp. 562.11/8.

33 Carta del Lic. Erasmo Lozano Rocha al presidente Ruiz Cortines, AGN, Ruiz Cortines, exp. 562.11/8.

34 Entrevista al señor Álvaro Obregón Tapia realizada por Nicolás Pineda Pablos, Hermosillo, 7 de diciembre de 1992. 
La Greene Cattle Company también arrendó terrenos, pero muchos menos. Una tercera empresa denunciada fue la Ganadera de Cananea, que operaba igual que las dos anteriores y también tenía como representante legal a Emilio Segura Jr. ${ }^{35}$ Una cuarta y última compañía que denunciaron fue el Banco de Cananea, creado por los mismos accionistas y sin el permiso de la Secretaría de Relaciones Exteriores. Dicha empresa era la propietaria del terreno Las Palomas, en Chihuahua, el cual constaba de alrededor de 115000 ha. Lozano Rocha también presentó documentos de una propiedad en la Bahía de Santiago, Colima, de alrededor de $700 \mathrm{ha}$. Supuestamente estas tierras pertenecían al señor Andrés O. Córdova, ciudadano mexicano, pero en realidad eran de Billy Greene, quien aparecía en el contrato de compraventa como representante legal de Córdova, a pesar de que firmó algunos documentos en calidad de "propietario". ${ }^{36}$

Las acusaciones mostraron que las propiedades arrendadas por Ranchos de Cananea, Greene Cattle Company y Ganadera de Cananea, ascendían a más de 200000 ha. A ellas se sumaban las 115000 ha del predio Las Palomas en Chihuahua y las 700 ha en la Bahía de Santiago, Colima. Lozano Rocha presentó números que sumaban entre 300000 y 350000 ha bajo el control de los Greene. En la opinión de Lozano Rocha, entre los miembros de la familia Greene y los de la Wiswall, el grupo controlaba alrededor de medio millón de ha en México. ${ }^{37}$

35 Carta de Rosina C. de Greene al presidente Ruiz Cortines, 30 de enero de 1954, AGN, Adolfo Ruiz Cortines, exp. 562.11/8.

${ }^{36}$ Carta del Lic. Erasmo Lozano Rocha al presidente Ruiz Cortines, AGN, Ruiz Cortines, exp. 562.11/8.

37 Carta del Lic. Erasmo Lozano Rocha al presidente Ruiz Cortines, AGN, Ruiz Cortines, exp. 562.11/8. En 1958, cuando el Partido Popular pidió la desaparición de los poderes, señaló el caso del latifundio Greene como una de las razones, y al igual que Lozano Rocha, dijo que las tierras controladas por los Greene ascendían a un cuarto de millón de hectáreas. Sesión del H. Congreso de la Unión del 12 de agosto de 1958, en Diario, 1955-1958, XLIII Legislatura. 
Aunque Rosina Cavazos acusó a cuatro compañías, se enfocó en atacar a Ranchos de Cananea, pues era la que tenía la mayor cantidad de tierras arrendadas. Dichas propiedades en Sonora, todas en la franja de los últimos $100 \mathrm{~km}$ de territorio nacional, daban como suma un latifundio de alrededor de un cuarto de millón de hectáreas.

Para Lozano Rocha el control de los Greene sobre las tierras se explicaba con el control sobre la vida pública de la región. Según el abogado, jueces y otras autoridades de Sonora estaban coludidas con los estadounidenses, por lo que había una pésima administración de justicia. Por último, Lozano Rocha dijo que el gobierno estatal puso trabas (aunque no mencionó cuáles) para que las autoridades federales no pudieran actuar. ${ }^{38}$

Las declaraciones de Rosina Cavazos, el trabajo de su abogado Erasmo Lozano Rocha y los documentos que hicieron públicos, fueron el principio del fin del latifundio. El movimiento campesino se vio alentado y personajes opuestos a la expropiación encontraron difícil descalificar el testimonio de Rosina Cavazos. Muchos políticos declararon su apoyo para recuperar el control de las tierras, las cuales revivieron el simbolismo del abuso y antinacionalismo ganado durante el porfiriato. Resultó contradictorio que un gobierno con retórica revolucionaria coexistiera con el control de la familia de uno de los magnates del porfiriato. Todo esto, a casi medio siglo de iniciada la revolución mexicana.

En sus memorias, Lozano Rocha señaló que el divorcio de Rosina Cavazos y Billy Greene fue uno de los factores que provocó el final del latifundio. Según él, los otros factores fueron la creación de la carretera Cananea-Ímuris-Agua Prieta y el movimiento campesino. ${ }^{39}$ Pero Lozano Rocha olvidó mencionar un

${ }^{38}$ Sesión del H. Congreso de la Unión del 12 de agosto de 1958, en Diario, 1955-1958, XLIII Legislatura.

${ }^{39}$ Lozano, Remembranzas, p. 438. 
factor clave en el debate: la actitud que tomó el gobierno de Estados Unidos ante las peticiones de expropiar el latifundio Greene.

En el contexto de la Guerra Fría, el gobierno estadounidense se mantuvo informado de las actividades sindicales, movimientos estudiantiles y campesinos de toda América Latina. No resulta extraño que vigilara celosamente su frontera con México. Los reclamos campesinos que pedían la expropiación del Latifundio Greene, pudieron ser vistos por las autoridades estadounidenses como consecuencia de la influencia comunista. Tal era la opinión de personajes como el empresario David N. Wiesley, quien dijo que el principal propósito de los comunistas era presionar al gobierno para que expropiara ranchos y tierras, particularmente si eran propiedad de estadounidenses. ${ }^{40}$

La embajada estadounidense coincidía, pero corrigió un poco la visión de Wiesley y dijo que los esfuerzos por expropiar empresas de extranjeros venían de grupos tanto comunistas como anticomunistas, pero ambos con la similitud de tener fuertes convicciones nacionalistas, pues según la embajada, el saqueo de los recursos naturales nacionales era a lo que más temían los mexicanos. Sin duda ese miedo fue producto de la coexistencia con acaudalados extranjeros que se consolidaron durante el porfiriato, quienes no sólo fueron grandes propietarios de tierras, minas y medios de producción, sino también quienes regían la vida política y social de algunas regiones, como fue el caso de William Cornell Greene en Cananea. Utilizando el mencionado miedo, distintas fuerzas de izquierda provocaron pérdidas a los empresarios estadounidenses, pues muchos mexicanos estaban

${ }^{40}$ Informe de David N. Wiesley, miembro de la Casa Wiesley S. A., 18 de agosto de 1954, NARA, RG 84, Embassy, Mexico City, classified general records, security-segregated GR 1941-49, 1950-1958, 350.21 Comunism 1953, 1954, 1955. 
dispuestos a movilizarse tras escuchar noticias de saqueos (dígase de petróleo, metales o bosques). A mediados de la década de 1950, el recurso del miedo al saqueo era, en opinión de la embajada estadounidense, la acusación predilecta para provocar expropiaciones. ${ }^{41}$

En el estado de Sonora las preocupaciones estadounidenses de expropiación siempre versaron en torno de la Compañía Richardson, también establecida durante el porfiriato, pero en las tierras del Valle del Yaqui (al sur de la entidad), dedicada al desarrollo agrícola, la colonización e irrigación. Una de las primeras acciones del gobierno de Álvaro Obregón Tapia (1955-1961) fue notificar a la Embajada de Estados Unidos que se revisarían los expedientes agrarios de 1940, donde algunos ejidatarios reclamaron tierras que podrían afectar las propiedades de la Compañía Richardson. En esa ocasión, la embajada respondió al gobierno de Sonora que se uniría a la revisión de los reclamos y ayudaría a dar una determinación, ${ }^{42}$ pero por otra parte, también advirtió al Departamento de Estado que en Sonora crecían los reclamos de expropiación y los estadounidenses eran el blanco usual. La Compañía Richardson ya había sido afectada con anterioridad: en 1940 con 1951 ha en Esperanza (municipio de Cajeme), y dos años después con 2347 ha en el municipio de Bácum. ${ }^{43}$

Al norte del estado, los reclamos de expropiación recayeron en las tierras del latifundio Greene, sobre todo después de

${ }^{41}$ Informe de la Embajada estadounidense, 9 de agosto de 1955, NARA, RG 59, Bureau of Inter-American affairs, office of the country director of Mexico, 1966-1975, Records relating to Mexico, compiled 1946-1975, documenting the period 1938-1975, HMS P 2, Container Id 2, Foreing relations-U. S., Mexico. ${ }_{42}$ Informe John M. Cates, primer secretario de la embajada estadounidense, 2 de diciembre de 1955, NARA, RG 84, Embassy, Mexico City, unclassified agrarian claims, 1940-1960, 236 Richardson Construction Co.

${ }_{43}$ Informe John M. Cates, primer secretario de la embajada estadounidense, 2 de diciembre de 1955, NARA, RG 84, Embassy, Mexico City, unclassified agrarian claims, 1940-1960, 236 Richardson Construction Co. 
las declaraciones de Rosina Cavazos en 1954 y del revuelo que causaron en la prensa. Dos características diferenciaban al caso del latifundio Greene del de la Compañía Richardson: se encontraba en la frontera y funcionaba con prestanombres. Aunado a esto, era una propiedad en la que los extranjeros mantenían un control más férreo. Una prueba de ello fueron los gambusinos encarcelados en 1954, quienes no cometieron otra falta que haber sido descubiertos mientras trabajaban en tierras arrendadas por la familia Greene. ${ }^{44}$ En mayo de 1957, el caso del latifundio llamó la atención de John F. Dulles, titular del Departamento de Estado (1953-1959).45

Desde los años de la presidencia de Harry S. Truman (19451953), Dulles propuso intervenir en la política de América Latina, siempre con el propósito de detener el comunismo y cuidar los intereses estadounidenses. ${ }^{46}$ Pudo hacerlo cuando fue nombrado secretario de Estado por el presidente Dwight D. Eisenhower (1953-1961). El ejemplo más emblemático de su política de intervención fue el caso de Guatemala en 1954, cuando Dulles, por medio de la Central Intelligence Agency (CIA), dirigida por su hermano menor Allen Dulles, apoyó un golpe de Estado para derrocar al gobierno de Jacobo Árbenz. ${ }^{47}$

Para informarse del caso del latifundio Greene, John F. Dulles acudió al secretario del Interior, Fred Andrew Seaton. Éste le advirtió que las propiedades controladas por la familia Greene corrían el peligro de ser expropiadas, y que Hugh Miller alentó al gobierno mexicano para que lo hiciera. Miller ocupaba la

${ }^{44}$ Peña y Chávez, “Ganadería”, p. 277.

${ }^{45}$ Marks, Power and Peace, p. xii; John Foster Dulles fue una figura política determinante durante los años posteriores a la segunda guerra mundial. Su desempeño como secretario de Estado durante la presidencia de Dwight D. Eisenhower lo colocó en una posición privilegiada para influir en la política mundial. Hasta la fecha, entre los historiadores no hay consenso sobre quién de los dos (Dulles o Eisenhower) tenía la voz de mando en el gobierno de Estados Unidos.

${ }^{46}$ Marks, Power and Peace, p. 98.

${ }_{47}$ Marks, Power and Peace, pp. 116-117. 
dirección de la Comisión Internacional de Parques y Bosques, subordinada al Departamento del Interior. Fred Seaton se enteró de que dicha comisión envió una carta (fechada el 5 de abril de 1957) al secretario de Agricultura en México, Gilberto Flores Muñoz, en la cual Hugh Miller expresó su deseo de usar las tierras del latifundio Greene para crear un parque transnacional en la frontera Arizona-Sonora. ${ }^{48}$ Seaton juzgó erróneas las acciones de Miller, pues su deseo de usar las tierras pudo ser interpretado por el gobierno mexicano como un deseo de verlas expropiadas y arrebatadas del control de los Greene. ${ }^{49}$ Seaton pidió que, desde ese momento en adelante, Miller no hiciera declaración alguna sin el consentimiento del Departamento del Interior. La misiva enviada a Gilberto Flores Muñoz podría darle libertades al gobierno mexicano para expropiar el latifundio y otras propiedades de estadounidenses. ${ }^{50}$

En cuanto a las características del latifundio Greene, Fred Seaton explicó a Dulles que se trataba de una propiedad de alrededor de 283279 ha, que fue creado y heredado por William Cornell Green, ubicado en tierras donde los extranjeros tenían prohibido tener propiedades, que era una sola propiedad la cual funcionaba a base de prestanombres, y los propietarios fácilmente podrían ser acusados de fraude fiscal y otras violaciones..$^{51} \mathrm{En}$ pocas palabras, el secretario del Interior confirmó todo lo que

\footnotetext{
${ }_{48}$ Este proyecto fue un intento para emular el Waterton-Glacier International Peace Park (Parque Internacional de la Paz Waterton-Glacier), un parque transnacional en territorios de Estados Unidos y Canadá.

${ }^{49}$ Carta de Fred Andrew Seaton, secretario del Interior, 16 de mayo de 1957, NARA, RG 84, Embassy, Mexico City, classified general records, securitysegregated GR 1941-49, 1950-58, 504.13 Parks 1956/57/58.

${ }^{50}$ Carta de Fred Andrew Seaton, secretario del Interior, 16 de mayo de 1957, NARA, RG 84, Embassy, Mexico City, classified general records, securitysegregated GR 1941-49, 1950-58, 504.13 Parks 1956/57/58.

${ }^{51}$ Carta de Fred Andrew Seaton, secretario del Interior, 16 de mayo de 1957, NARA, RG 84, Embassy, Mexico City, classified general records, securitysegregated GR 1941-49, 1950-58, 504.13 Parks 1956/57/58.
} 
habían expuesto cuatro años antes Rosina Cavazos de Greene y su abogado. Seaton se comunicó con los representantes legales de los Greene en México. Los abogados de la familia estadounidense le aseguraron que las propiedades estaban fuera de peligro pues oficialmente eran de mexicanos y no había razones para que fueran afectadas. Sin embargo, Seaton sabía que grupos de campesinos y partidos políticos reclamaban la expropiación. Según este político estadounidense, los abogados de los Greene estaban demasiado confiados. Para la mala suerte de la familia estadounidense, grupos campesinos ${ }^{52}$ tuvieron conocimiento de la carta de Hugh Miller y, al enterarse del proyecto de crear un parque transnacional, reclamaron con más enjundia la expropiación. ${ }^{53}$

Fred Seaton coincidía en que la expropiación era inevitable. Además de la presión y el error de Miller, el secretario del Interior encontró otro factor que complicaba mantener la posesión de las tierras: los Greene no estaban de acuerdo en la decisión de vender o no, y en caso de hacerlo a qué precio. Por dichas diferencias, aunadas a litigios legales entre los mismos miembros de la familia, Seaton consideró que no podría haber negociaciones de compraventa al menos durante un año. Los propietarios necesitaban "mucho más tiempo" para negociar entre ellos, antes de hacerlo con el gobierno del presidente Adolfo Ruiz Cortines (1952-1958). Seaton cerró su informe con una advertencia: la intervención del gobierno estadounidense en el caso crearía una "alarma de grandes magnitudes" que a su vez podría provocar una serie de expropiaciones a lo largo de toda la frontera. ${ }^{54}$

52 Aunque no se especifica cuáles eran estos grupos de campesinos, posiblemente se trató de miembros del Partido Popular, de la Unión General de Obreros y Campesinos de México o del Partido Comunista Mexicano, pues Fred Seaton los catalogó como "frentes comunistas".

${ }^{53}$ Carta de Fred Andrew Seaton, secretario del Interior, 16 de mayo de 1957, NARA, RG 84, Embassy, Mexico City, classified general records, securitysegregated GR 1941-49, 1950-58, 504.13 Parks 1956/57/58.

${ }^{54}$ Carta de Fred Andrew Seaton, secretario del Interior, 16 de mayo de 1957, 
Fred Seaton demostró un amplio conocimiento del caso; por lo tanto, John F. Dulles le pidió que propusiera cuál debía ser la postura de su gobierno; afortunadamente para los mexicanos, Seaton resultó ser muy prudente. Las difíciles circunstancias legales del latifundio, así como el deseo de funcionarios del gobierno de Arizona de que se expropiara (para dar paso a la creación de un parque transnacional), motivaron que Seaton propusiera mantener una postura neutral y no apoyar a ninguno de los involucrados..$^{55}$

En la visión de Seaton, cualquier protección a los Greene sería interpretada por los mexicanos como una intervención en la política nacional. En cuanto a la creación del parque, afirmó que era un proyecto viable. La expropiación de las tierras sería una noticia bien recibida por las autoridades de Arizona, pero sólo si el gobierno mexicano accedía a usarlas para la creación de un parque transnacional. La obtención de las tierras y su uso seguían en suspenso; por lo tanto, Seaton recomendó discreción y que no se mencionase el proyecto del parque,$^{56}$ pues sabía que si se expropiaba el latifundio, incluso si el gobierno mexicano quisiera crear el parque, el proyecto no estaba asegurado por los múltiples intereses que había sobre las tierras. Los que exigían la expropiación en Sonora lo hacían con miras a repartir las tierras, no a crear espacios de recreación. Si el gobierno mexicano no hacía público su deseo de crear el parque, de nada le serviría al gobierno estadounidense alentar la expropiación.

\footnotetext{
NARA, RG 84, Embassy, Mexico City, classified general records, securitysegregated GR 1941-49, 1950-58, 504.13 Parks 1956/57/58.

${ }_{55}$ Carta de Fred Andrew Seaton, secretario del Interior, 13 de junio de 1957, NARA, RG 84, Embassy, Mexico City, classified general records, securitysegregated GR 1941-49, 1950-58, 504.13 Parks 1956/57/58.

${ }^{56}$ Carta de Fred Andrew Seaton, secretario del Interior, 13 de junio de 1957, NARA, RG 84, Embassy, Mexico City, Classified General Records, SecuritySegregated GR 1941-49, 1950-58, 504.13 Parks 1956/57/58.
} 
De ahí se deriva la postura de Seaton, quien insistió en no negociar nada hasta tener asegurado que el gobierno mexicano adquiriera las tierras, que se abriera la posibilidad de usarlas para el parque y que los Greene tuvieran asegurada una compensación financiera. En caso de que la expropiación ocurriera, recomendó que el gobierno estadounidense actuara respetuosamente con cualquier disposición que tomara el gobierno mexicano. Para Seaton, era un caso por el cual no valía la pena entrar en conflicto con el vecino del sur. ${ }^{57}$

John F. Dulles tomó la postura de Seaton, quien, aunque dijo que había "frentes comunistas" entre quienes reclamaban la expropiación, jamás mencionó que ésta viniera acompañada de amenazas o riesgos para la frontera estadounidense. Por el contrario, Seaton aprobó el interés de crear el parque y lo catalogó como un proyecto viable. Más alarmista fue la opinión del embajador estadounidense en México, Francis White, ${ }^{58}$ quien dos semanas después, en una plática con Antonio Carrillo Flores, secretario de Hacienda (1952-1958), expresó su preocupación por los estragos de la "influencia comunista" en los estados norteños. ${ }^{59}$ White no mencionó las presiones para expropiar el latifundio Greene, pero éstas bien pudieron ser parte de lo que él calificaba como "influencia del bloque soviético".

${ }^{57}$ Carta de Fred Andrew Seaton, secretario del Interior, 13 de junio de 1957, NARA, RG 84, Embassy, Mexico City, classified general records, securitysegregated GR 1941-49, 1950-58, 504.13 Parks 1956/57/58.

58 Conocido como "cosmopolita culto", Francis White fue enviado a México como embajador para el periodo de 1953 a 1957. Organizó encuentros entre los presidentes Adolfo Ruiz Cortines y Dwight Eisenhower, y ayudó a mejorar la imagen de Estados Unidos luego del golpe de Estado en Guatemala en 1954. Mantuvo una buena relación con Luis Padilla Nervo, secretario de Relaciones Exteriores (1952-1958). Al finalizar su gestión, el gobierno mexicano le otorgó la condecoración del Águila Azteca. Cid, "Francis White”.

59 Conversación del embajador Francis White con Antonio Carrillo Flores, secretario de Hacienda, 26 de junio de 1957, NARA, RG 84, Embassy, Mexico City, Classified General Records, Security-Segregated GR 1941-49, 1950-58, 350-México 1957. 
Fred Andrew Seaton planteó su postura a John F. Dulles en 1957, un año antes de que los miembros de la Unión General de Obreros y Campesinos de México (UGOCM) invadieran los terrenos del latifundio Greene. Hasta entonces, el gobierno de Estados Unidos se mantuvo al margen del tema. Tanto la Comisión Internacional de Parques y Bosques como el gobierno de Arizona esperaron deseosos la creación del parque transnacional, pero no manifestaron su entusiasmo para no afectar las negociaciones de compraventa entre los Greene y el gobierno mexicano.

Las declaraciones de Rosina Cavazos y la relativamente abierta postura del gobierno de Estados Unidos fueron elementos para que el gobierno mexicano pudiera expropiar el latifundio Greene. El movimiento campesino fue un catalizador de efectos retardados, pues las organizaciones campesinas llevaban años con sus reclamos. Los miembros de las sociedades ejidales "Jacinto López Moreno" y "Prof. Ramón Oquita Montenegro" (nombres de los dos líderes campesinos que más reclamaron la expropiación) le explicaron al presidente Ruiz Cortines en 1954 que se encontraban en la pobreza y aunque tenían organizadas sus sociedades ejidales, seguían sin recibir tierras. ${ }^{60}$ Como solución provisional se dedicaron a vender bacanora ${ }^{61}$ y leña, pero se vieron privados de aquel sustento pues cortaban los agaves y árboles en tierras del latifundio y los capataces de las compañías Greene los sacaban de los territorios con violencia y amenazas. ${ }^{62}$

${ }^{60}$ Carta de los miembros de los ejidos “Jacinto López Moreno" y "Prof. Ramón Oquita Montenegro”, 24 de enero de 1954, AGN, Adolfo Ruiz Cortines, exp. 464.1/9.

${ }^{61}$ Bebida alcohólica tradicional de Sonora, parecido al mezcal; es un destilado incoloro y de alta graduación alcohólica.

${ }^{62}$ Telegrama de los campesinos del centro de la población "20 de noviembre", 21 de enero de 1954, AGN, Adolfo Ruiz Cortines, exp. 562.11/8. 
Al pedir ayuda a las autoridades locales, estas comunicaron que la familia Greene aceptó permitir la tala en uno de sus predios, el Huacho, pero éste se encontraba en Arizona y sólo podrían ir aquellos con la capacidad de pagar los impuestos de importación a la aduana, controlada por Ramón Morales Ibarra, quien se apoderó del monopolio de la leña. ${ }^{63}$

Los campesinos del centro de población "20 de noviembre", también en Cananea, notificaron a la presidencia ser víctimas de las mismas circunstancias. Estos grupos campesinos pasaron años exigiendo la expropiación de las tierras, pero sus reclamos no eran escuchados, por lo que la familia Greene les envió la sugerencia de migrar a Estados Unidos en busca de mejores oportunidades. Alrededor de 1000 campesinos informaron que los Greene mantuvieron una constante campaña de desprestigio contra el gobierno mexicano, y que informaban a la población de Cananea que las autoridades mexicanas jamás harían justicia a los solicitantes, por lo que lo más prudente era dejar los reclamos. El capítulo de represión más sonado se dio en febrero de 1958, cuando capataces de las compañías ganaderas Greene, apoyados por elementos del orden público, desalojaron a los pobladores del pueblo de Cuitaca, ubicado en las tierras del latifundio. Los desalojados fueron subidos a camiones contra su voluntad para ser trasladados. Mientras se los llevaban, vieron cómo los capataces destruían sus casas. A pesar de que había nevado, los desalojados (alrededor de cien) fueron dejados en un parque de Cananea a la intemperie. Con la ayuda de Jacinto López y los mineros de la ciudad, se negoció que las familias se refugiaran en un estadio de beisbol. ${ }^{64}$

Los campesinos de la UGOCM tenían un año planeando invadir las tierras. En la campaña electoral de Adolfo Ruiz Cortines,

63 Telegrama de los campesinos del centro de la población "20 de noviembre", 21 de enero de 1954, AGN, Adolfo Ruiz Cortines, exp. 562.11/8.

64 Peña y Chávez, “Ganadería”, p. 277. 
en 1952, el candidato presidencial visitó Sonora y prometió que durante su sexenio se expropiaría el latifundio Greene. Un año antes de terminar su gestión, Ruiz Cortines no había cumplido su promesa. El líder nacional de la UGOCM, Jacinto López Moreno, se reunió con el presidente a inicios de 1957. Después del encuentro, convocó a sus afiliados al Congreso General de Solicitantes de Nuevos Centros de Población Agrícola del Noroeste, celebrado en marzo de ese año en Los Mochis, Sinaloa. En esta reunión, Jacinto López informó que el presidente le prometió cumplir su promesa, pero le pidió paciencia. Sin embargo, Jacinto López concluyó que, si Ruiz Cortines no cumplió su palabra en cinco años de gobierno, mucho menos lo haría en el último año, y por ello el líder campesino decidió tomar medidas más directas. Así, la UGOCM redactó un ultimátum en el cual advirtió al gobierno federal que si en un año no se realizaban las expropiaciones reclamadas en Sonora, Sinaloa y Baja California, invadirían los terrenos en cuestión. ${ }^{65}$

En esa misma ocasión, Jacinto López le confesó a sus hombres de más confianza que la entidad que más le preocupaba era Sonora. En Sinaloa gobernaba Gabriel Leyva Velázquez, hombre no identificado como protector de los terratenientes, quien incluso fue líder de la Confederación Nacional Campesina. Además, era un político con el que Vicente Lombardo Toledano mantenía buena relación, ${ }^{66}$ y Toledano era el líder el Partido Popular, organización a la que la UGOCM estaba afiliada. En Baja California el gobernador era Braulio Maldonado, político

${ }^{65}$ Ramírez, Guadarrama, Conde, León, Martínez y Martínez, “Los resultados de la modernización”, p. 191.

${ }^{66}$ Informe de William P. Hudson, segundo secretario de la embajada estadounidense, 12 de febrero de 1954, NARA, RG 84, Embassy, Mexico City, classified general records, security-segregated GR 1941-49, 1950-58, 350-Mexico 1954. Gabriel Leyva Velázquez mantenía buenas relaciones con los líderes del Partido Popular, al grado de que cuando Vicente Lombardo Toledano intentó crear una coalición de izquierda, invitó a Leyva para que formara parte de ella. 
de conocidas simpatías cardenistas y además amigo de Jacinto López. ${ }^{67}$ A diferencia de los anteriores, el gobernador de Sonora, Álvaro Obregón Tapia, era identificado como un protector de los terratenientes, pues él mismo era uno de ellos. Además, el hijo del expresidente y José Santos Gutiérrez, tesorero del estado, mantenían muy buena relación con la familia Greene. ${ }^{68}$

La presidencia ignoró el ultimátum y la UGOCM inició las invasiones en febrero de 1958. El nuevo embajador de Estados Unidos en México, Robert C. Hill, informó al Departamento de Estado que un grupo de campesinos, liderados por Jacinto López, había invadido tierras cerca de Culiacán. ${ }^{69}$ Como lo esperaba la UGOCM, el gobernador Gabriel Leyva buscó la reconciliación y no se opuso a las invasiones. Tanto Leyva como Gilberto Flores Muñoz, secretario de Agricultura, se encontraban en la Ciudad de México cuando los campesinos tomaron las tierras. Ambos viajaron apresurados al estado norteño pero antes, según lo informado por el embajador, Ruiz Cortines dio órdenes a Flores Muñoz de resolver el conflicto con métodos estrictamente pacíficos. ${ }^{70}$ Esta postura posiblemente se debió al deseo de mantener tranquilo el contexto preelectoral de ese año.

El embajador notificó la afluencia de campesinos a Cananea y un pequeño intento de invasión, efectuado el 5 de febrero de 1958, que fue repelido por la policía estatal. La experiencia en Sinaloa fue contraria: a los campesinos se les permitió mantener sus campamentos y Gilberto Flores Muñoz les reconoció

${ }^{67}$ Ochoa, Biografía de Jacinto López Moreno, p. 15.

${ }_{68}$ Moncada, Diez en el poder, p. 103.

${ }^{69}$ Informe de Robert C. Hill, embajador de EUA en México, 19 de febrero de 1958, NARA, RG 84, Embassy, Mexico City, classified general records, security-segregated GR 1941-49, 1950-58, 501 Lands 1956/57/58.

${ }^{70}$ Informe de Robert C. Hill, embajador de EUA en México, 19 de febrero de 1958, NARA, RG 84, Embassy, Mexico City, classified general records, security-segregated GR 1941-49, 1950-58, 501 Lands 1956/57/58. 
de manera pública su derecho a las tierras que invadían, ${ }^{71}$ esto incluso antes de reunirse con ellos.

El intento de invasión en Cananea provocó que las compañías ganaderas Greene tomaran medidas para evitar posibles futuras invasiones: sacrificaron muchas cabezas de ganado y destruyeron pozos de agua. Con esto, garantizaron que el ganado no fuera a caer en manos de los invasores y dificultaron el acceso al agua a cualquiera que quisiera acampar en sus tierras. ${ }^{72}$ Estas acciones coincidieron con el anuncio de la prensa -aliada al gobierno- de que las autoridades de Cananea se preparaban para la llegada del "líder filocomunista" Jacinto López, quien tenía la intención de dirigir las invasiones al latifundio Greene. ${ }^{73}$ En Sinaloa se llegó a un acuerdo después de pláticas, verificaciones de títulos de propiedad y consultas con Ruiz Cortines. Gilberto Flores Muñoz anunció la expropiación de las tierras invadidas ubicadas en el valle de Culiacán. ${ }^{74}$ En la segunda mitad del mismo mes (marzo), los campesinos de la UGOcm invadieron terrenos en Baja California con el apoyo del gobernador Braulio Maldonado. Ese caso tuvo una resolución más pronta y, para el último día del mes, Flores Muñoz anunció la expropiación y el futuro reparto de tierras en el valle de Mexicali. ${ }^{75}$

Luego de las invasiones en Sinaloa y Baja California, los miembros de la UGOCM hicieron un alto. Se solidarizaron con la campaña de López Mateos, quien visitó el estado de Sonora en abril y se reunió con los líderes del Partido Popular, entre ellos

\footnotetext{
${ }^{71}$ Informe de Robert C. Hill, embajador de EUA en México, 19 de febrero de 1958, NARA, RG 84, Embassy, Mexico City, classified general records, security-segregated GR 1941-49, 1950-58, 501 Lands 1956/57/58.

72 Telegrama de campesinos de Cananea dirigido a la Presidencia, 2 de marzo de 1958, AGN, Adolfo Ruiz Cortines, exp. 562.11/8.

73 “Esperan a Jacinto López en Cananea por segunda ocasión”, El Imparcial (4 mar. 1958).

74 “Salió Obregón a Navojoa para recibir a F. M.”, El Imparcial (17 mar. 1958). 75 "Pasa al dominio de la nación un latifundio en la Baja California", El Imparcial (31 mar. 1958).
} 
Jacinto López. El candidato presidencial priista visitó Cananea, ${ }^{76}$ población que se encontraba tranquila y que no registraba nuevos intentos de invasión. El mes de mayo transcurrió con la misma tranquilidad. A inicios de junio Jacinto López seguía sin visitar Cananea. En lugar de eso, estuvo en Sinaloa para acudir a un acto en el que Flores Muñoz puso en manos de la UGOCM las tierras expropiadas en el predio El Venadillo. ${ }^{77}$

A inicios de julio, a pesar de que los campesinos de la UGOCM habían detenido sus invasiones desde el mes de marzo, la prensa aliada al gobierno siguió satanizándolos: se advertía que el “comunista" Jacinto López y otros líderes "de filiación roja” se encontraban en Cananea y planeaban agitar a la población para impedir el ejercicio de las elecciones presidenciales. ${ }^{78}$ Contrario a lo dicho por la prensa local, luego de la gira de López Mateos por Sonora los líderes de la UGOCM permanecieron tranquilos. Jacinto López tenía buena relación con el candidato presidencial, por lo que no tuvo intenciones de obstruir las elecciones.

Una semana después de transcurridos los comicios, el día 11 de julio iniciaron las invasiones al latifundio Greene. Los campamentos se instalaron en donde estaba el poblado de Cuitaca, desalojado un año antes. Los habitantes de dicha localidad, que hasta entonces habían vivido en el estadio de beisbol de Cananea, se unieron a las invasiones e hicieron que el movimiento tomara un fuerte peso simbólico. ${ }^{79} \mathrm{La}$ prensa oficialista los criticó y dijo que perjudicarían las negociaciones que sostenía el gobierno con la familia Greene. ${ }^{80}$ Dos días después Ángel Carvajal, secretario de Gobernación, declaró prohibidas las manifestaciones postelectorales en México y desató el debate de si

\footnotetext{
76 “López Mateos en Sonora”, El Imparcial (24 abr. 1958).

77 OchоA, Biografía de Jacinto López Moreno, 1991.

78 “Tranquilidad en Cajeme”, El Imparcial (5 jul. 1958).

79 "Declaraciones del Sr. Jacinto López en Cananea", El Heraldo del Yaqui (11 jul. 1958).

80 "Causan disturbios los pepinos en Cananea", El Imparcial (10 jul. 1958).
} 
la prohibición iba dirigida a detener las invasiones campesinas o los movimientos de inconformidad electoral. ${ }^{81} \mathrm{~A}$ diferencia de lo ocurrido en Sinaloa y Baja California, a menos de una semana de iniciadas las invasiones, la fuerza pública sitió a los campesinos y arrestó a Jacinto López y a cinco de sus colaboradores. ${ }^{82}$

El factor que determinó la diferencia en el caso sonorense fue la actitud del Ejecutivo estatal. Obregón Tapia se negó a que se expropiara el latifundio Greene y en parte por mantener buena relación con los Greene, en parte porque él mismo era un terrateniente. Con la ayuda de la prensa oficialista, sus facultades como gobernador, la complicidad del general Juan José Gastélum (jefe de la $4^{\mathrm{a}}$ zona militar) y de otros personajes como el expresidente Emilio Portes Gil, el gobernador combatió hasta donde pudo la expropiación.

\section{VII}

El procurador de justicia del estado de Sonora emitió una orden de arresto contra Jacinto López, quien fue a parar a prisión y al día siguiente su esposa telefoneó a varias personas en busca de auxilio; entre otros, habló con Gilberto Flores Muñoz. ${ }^{83}$ Las protestas no se hicieron esperar y uniones campesinas manifestaron su solidaridad con los detenidos, tal fue el caso de las uniones de Tlacochahuaya y la de Trinidad de las Huertas, ambas del estado de Oaxaca, y las de Aljojuca y Tecamachalco, de Puebla. Lo mismo el Sindicato Nacional de Trabajadores

\footnotetext{
${ }^{81}$ Bartolomé Delgado de León, “No habrá invasión de latifundios”, El Heraldo del Yaqui (12 jul. 1958).

${ }^{82}$ Los otros detenidos fueron: Francisco Saavedra León, quien participó en las elecciones como candidato a diputado federal por el Partido Popular; Antonio Parada, en ese momento secretario estatal de la UGOCM; Martín Calvo, Ismael Valenzuela y Enrique Amador, miembros de la UGOCM en Cananea.

83 “Jacinto López Moreno aprehendido en Cananea por la judicial”, El Heraldo del Yaqui (15 jul. 1958).
} 
de la Educación sección Sinaloa, los vecinos de Pátzcuaro, Michoacán, el Sindicato de Electricistas de la Ciudad de México, la Liga Revolucionaria de Obreros y Campesinos de Jalisco, y por supuesto todas las delegaciones estatales de la UGOCM y el Partido Popular. ${ }^{84}$

A Jacinto López y sus colaboradores se les acusó de despojo, asonada, motín y conspiración, y fueron remitidos a la cárcel de Cananea. ${ }^{85}$ Muchos campesinos se congregaron fuera de la prisión para protestar y algunos amenazaron con tomar el edificio por la fuerza para liberar a los detenidos. ${ }^{86}$ No hubiera sido la primera vez. Ya se había dado un caso parecido en 1938, cuando al ser arrestado Jacinto López, sus seguidores (armados con rifles y machetes) acudieron a su rescate y lo liberaron. ${ }^{87}$ Ante este riesgo, las autoridades optaron por transferir a los presos a la penitenciaría de Hermosillo, donde fueron aislados y se les negó la fianza. ${ }^{88}$

Sólo se permitió que una persona los visitara y el elegido fue Humberto Ochoa, concuño de Jacinto. Humberto se encargó de llevarles comida, café, cigarros (Jacinto era un fumador empedernido), el periódico y demás provisiones, pero también fue el contacto del líder campesino con el exterior. Humberto fue el medio de comunicación entre Jacinto López y Adolfo Ruiz

\footnotetext{
${ }^{84}$ AGN, Adolfo Ruiz Cortines, exp. 562.11/8.

85 "Niegan a Jacinto López la libertad bajo fianza", El Imparcial (16 jul. 1958).

${ }^{86}$ Moncada, Diez en el poder, p. 100.

${ }^{87}$ En aquella ocasión Jacinto López fue arrestado de manera arbitraria en Pueblo Yaqui. Al caer la noche, un grupo de aproximadamente 200 campesinos armados, provenientes de poblaciones aledañas a Ciudad Obregón, rodearon la comandancia y amenazaron con entrar a la fuerza. Sin otra opción, los oficiales ahí presentes entregaron sus armas y permitieron que los campesinos entraran para liberar a Jacinto López. BANTJEs, As if Jesus Walked on Earth, p. 189.

88 "Niegan a Jacinto López la libertad bajo fianza", El Imparcial (16 jul. 1958).
} 
Cortines, Gilberto Flores Muñoz, Vicente Lombardo Toledano, el general Lázaro Cárdenas y Braulio Maldonado. Este último ofreció su ayuda al movimiento, por lo que Humberto Ochoa se prestó para hacer un viaje exprés a Baja California, donde recibió de manos del propio Maldonado apoyos económicos, despensas y cobijas para los campesinos que continuaban en la invasión del latifundio en Cananea. ${ }^{89}$

Las noticias no sólo hicieron que se examinara la situación de los aprehendidos, también generaron debate en torno del latifundio Greene. El Partido Popular se adjudicó el mérito de ser quienes luchaban por la expropiación, mientras que la Secretaría de Agricultura dijo que Flores Muñoz estaba en negociaciones con la familia Greene desde hacía más de un mes, y por lo tanto el mérito de obtener las tierras debía ser únicamente del presidente Ruiz Cortines. ${ }^{90}$ Lo anterior era medianamente cierto, pues era verdad que Ruiz Cortines ya había dado orden de negociar la compraventa, pero lo que la Secretaría de Agricultura omitió decir era que los Greene se habían negado a vender. ${ }^{91}$ Gilberto Flores Muñoz declaró que la resolución del caso Greene se acercaba, pero no dio detalles sobre cuándo ni cómo. ¿Se iba a comprar la propiedad o se iba a expropiar?

Se concedió a la prensa local una entrevista con Jacinto López, quien salió tranquilo de su celda y regaló a los reporteros bellotas que traía desde Cananea. Dijo que la lucha por expropiar el latifundio venía desde 1933 y acusó de antiagraristas a varios agricultores de Cajeme, al expresidente Emilio Portes Gil y otros

\footnotetext{
${ }^{89}$ Humberto Ochoa cumplió un papel primordial para el movimiento campesino. Todas sus andanzas como medio de comunicación entre los presos y el exterior, las relata detalladamente en las páginas de su libro ОсноA, Biografía de Jacinto López Moreno.

90 “Nadie podrá atribuirse el rescate del gran latifundio", El Imparcial (21 jul. 1958).

${ }^{91}$ Entrevista al exgobernador Álvaro Obregón Tapia, realizada por Nicolás Pineda Pablos, Hermosillo, 7 de diciembre de 1992.
} 
funcionarios. ${ }^{92}$ Los reporteros le preguntaron si pensaba que Ruiz Cortines obstruía la expropiación, a lo que Jacinto contestó que en su opinión el presidente hubiera expropiado el latifundio mucho antes, pero no podía hacerlo por no tener apoyo del gobierno estatal. Más que crearle problemas al presidente, para Jacinto, las invasiones eran una herramienta con la que Ruiz Cortines podría "sacudirse a los políticos locales". Rehuyó hablar de su detención y de los cargos de los que se le acusaba, pero advirtió que, de no ser liberado, la UGOCM movilizaría a 50000 campesinos para manifestarse. ${ }^{93}$ De todo lo anterior, las declaraciones que más causaron revuelo fueron aquellas de que Ruiz Cortines quería expropiar, pero el gobierno estatal se lo obstruía. ${ }^{94}$

Los detenidos consiguieron los servicios de Pedro Galindo, abogado que pidió la libertad de sus clientes por falta de pruebas. ${ }^{95}$ También solicitó que las audiencias para tratar el caso se realizaran ante el Juzgado Federal del Distrito de Nogales y no ante el Supremo Tribunal de Justicia del Estado de Sonora, pues denunció que las instancias de la entidad estaban al servicio del gobernador y en alianza con los Greene. ${ }^{96}$ Con el pasar de los días se agrandó la figura de Jacinto López y fue visitado por reporteros, líderes campesinos y personalidades de mayor importancia, como Demetrio Vallejo, líder del Sindicato Nacional de Ferrocarrileros, y Francisco Guerrero, emisario de Lázaro Cárdenas. ${ }^{97}$

Una nueva noticia acaparó los reflectores: se complicó la compra del latifundio. Aunque la familia Greene había pactado un

\footnotetext{
92 “Entrevistan a Jacinto López”, El Imparcial (23 jul. 1958).

93 "Entrevistan a Jacinto López", El Imparcial (23 jul. 1958).

94 "Ni un centavo debe pagarse", El Heraldo del Yaqui (23 jul. 1958); "Habló desde la cárcel”, Diario del Yaqui (23 jul. 1958).

${ }^{95}$ Enguerrando Tapia, "Jacinto López Moreno en la peni", El Imparcial (24 jul. 1958).

96 “Audiencias en el proceso de Jacinto", El Imparcial (31 jul. 1958).

97 Moncada, Diez en el poder, p. 100.
} 
precio, se hizo público el testamento de Mary Greene Wiswall (fallecida en 1954 y viuda de William Cornell Greene), quien dejó de albacea a Kirk Greene, personaje de la familia etiquetado por la prensa como uno de los más reacios a vender. Además, en las negociaciones se mostró una cláusula de propiedad en la que se especificaba que los herederos no tenían autorización para vender, hipotecar o empeñar los territorios. ${ }^{98}$ Lo anterior hizo más previsible la expropiación.

\section{VIII}

Antonio Carrillo Flores, secretario de Hacienda y quien en esos meses asumiría la embajada mexicana en Estados Unidos, solicitó una reunión con el embajador estadounidense Robert Hill. El encuentro, celebrado a inicios de agosto, duró todo el día. Algunos de los temas que Carrillo Flores quería examinar eran: el latifundio Greene, la exportación de petróleo mexicano, los reportes de la embajada estadounidense referentes a la adversa situación económica en México y la filtración de comunistas en el gobierno. ${ }^{99}$ Robert Hill expresó interés en hablar de los problemas y reclamos de campesinos por las tierras en el Sábalo (Sinaloa) y sobre la petición del gobierno mexicano para que le fuera devuelto a México el terreno conocido como El Chamizal (Chihuahua). Sin embargo, el embajador estadounidense rehuyó hablar sobre el latifundio Greene, ${ }^{100}$ quizá por seguir la orden de John F. Dulles de mantenerse neutrales.

\footnotetext{
98 "Nuevas complicaciones en la compra del latifundio", El Imparcial (8 ago. 1958).

${ }^{99}$ Informe de Robert C. Hill, embajador estadounidense, 9 de agosto de 1958, NARA, RG 84, Embassy, Mexico City, classified general records, security - segregated GR 1941-49, 1950-58, 350 Mexico 1958.

${ }^{100}$ Informe de Robert C. Hill, embajador estadounidense, 9 de agosto de 1958, NARA, RG 84, Embassy, Mexico City, classified general records, security-segregated GR 1941-49, 1950-58, 350 Mexico 1958.
} 
El gobierno de Estados Unidos se abstuvo de intervenir en las negociaciones del gobierno mexicano con la familia Greene, las cuales entraron en un mar de confusiones. A pesar de que Jacinto López acusó a Emilio Portes Gil de fungir como protector de los estadounidenses, el expresidente negó estas acusaciones. A su vez, Kirk Greene negó lo informado por el Imparcial de que era el heredero más reacio a no vender, como lo publicó dicho diario. Kirk alegó ser partidario de llegar a un acuerdo de compraventa y negó la existencia de una cláusula en el testamento que les prohibía vender. El estadounidense insistió en que el albacea del testamento recayó en los que querían vender y no al contrario. ${ }^{101}$ Resultó irrelevante lo que señalaba el testamento, pues a los pocos días el juez de primera instancia mixto en el distrito judicial de Sonora rechazó la validez del testamento por considerar que no fue creado bajo los procedimientos establecidos por la ley mexicana. ${ }^{102}$

A los pocos días, el Partido Popular (PP) pidió la desaparición de los poderes en el estado. Los líderes del pp respaldaron su petición con las irregularidades del proceso electoral de ese año y las protestas que desataron en la región, aunque también mencionaron el caso del latifundio Greene y exigieron su expropiación como un acto de reivindicación nacional. Además de señalar la pobreza e injusticias que provocaba el latifundio, culparon al gobernador Obregón Tapia de anteponer los intereses del empresariado extranjero sobre los derechos de los trabajadores mexicanos, ${ }^{103}$ mismo discurso que usaron los huelguistas de 1906.

Al borde del desenlace, existían muchas dudas tanto para la población en general como para los grupos inmiscuidos en el tema: ¿Ruiz Cortines quería o no expropiar? ¿Obregón Tapia

\footnotetext{
101 “Fallaron una petición de Jacinto López”, El Imparcial (13 ago. 1958).

102 "Es rechazado el testamento", El Imparcial (8 ago. 1958).

${ }_{103}$ Sesión del H. Congreso de la Unión del 18 de agosto de 1955, en Diario, 1955-1958, XLIII Legislatura.
} 
intervenía en la decisión? ¿Emilio Portes Gil era o no protector de los Greene? ¿Los Greene no querían vender? ¿O esta era una impresión que quería crear el gobierno mexicano para usarla como excusa y expropiarlos?

IX

Poco después de la petición de desaparición de los poderes, la cual el H. Congreso de la Unión resolvió "no ha lugar", se publicó el decreto presidencial que expropió 261000 ha del latifundio Greene. ${ }^{104}$ Hubo gran júbilo en Sonora, sobre todo en Cananea, y el Congreso declaró día festivo. ${ }^{105}$ Se anunció la comitiva que tomaría la posesión de las tierras, encabezada por el secretario de Agricultura y el gobernador. ${ }^{106}$ Flores Muñoz fue a Cananea e izó la bandera mexicana en las tierras recuperadas por la nación. ${ }^{107}$

Jacinto López y Flores Muñoz tenían buena relación, al grado de que temprano ese año el primero expresó su gusto por la posible candidatura presidencial del otro, así que no faltó quien sospechara que las invasiones y su resolución se efectuaron con el propósito de agrandar la figura de Flores Muñoz e impulsar sus aspiraciones presidenciales. ${ }^{108}$ Sin embargo, las invasiones y el desempeño de Flores Muñoz en la resolución del conflicto no se realizó sino hasta después de anunciada la candidatura de López Mateos y después del día de las elecciones. Por lo tanto, resulta poco probable que el movimiento tuviera un móvil en las aspiraciones presidenciales de Flores Muñoz.

104 Almada, Breve historia de Sonora, p. 152.

105 "Día de festejo en Sonora por la expropiación”, Diario del Yaqui (22 ago. 1958).

106 “México tomó posesión del latifundio”, El Imparcial (22 ago. 1958).

107 “Jacinto López celebra en la peni”, El Heraldo del Yaqui (22 ago. 1958).

108 Hernández, Presidencialismo, pp. 114-115. 
El mismo día que se anunció la expropiación, el reportero Enguerrando Tapia (de El Imparcial) visitó a los encarcelados. En palabras de Tapia, la prisión de Hermosillo vivía la misma alegría que el resto de la sociedad sonorense. Jacinto López declaró que incluso si se mantenían privados de su libertad por diez años, el sacrificio valía la pena. ${ }^{109}$ En un telegrama, el líder campesino felicitó a Ruiz Cortines; le dijo que con la expropiación se colocaba "en la fila de los grandes patriotas de nuestra historia", ${ }^{110}$ sin reclamar o siquiera mencionar el encierro que cumplían él y sus colegas de la UGOCM. Con la expropiación anunciada, se especuló que los detenidos pronto estarían en libertad, ${ }^{111}$ pero no fue así. El influyente priista y reportero local José A. Mendívil ${ }^{112}$ intercedió por Jacinto López. En un desplegado dirigido al procurador de Justicia del estado, Mendívil exigió la libertad de los presos con el argumento de que, al ser expropiado el latifundio, ya no tenía caso privar de su libertad a los líderes de la invasión. Consideró "injusto que los que hicimos menos y hasta los que no hicieron nada, estemos de fiesta [por la expropiación] y los que más hicieron, aunque sea a su manera, estén en prisión”. Para Mendívil, el júbilo de la expropiación debía pertenecer a todos los mexicanos sin importar su partido político o ideología. ${ }^{113}$

De todas las publicaciones, sólo el Diario del Yaqui se preocupó por publicar la postura del gobierno estadounidense respecto a la expropiación. Este periódico informó que el Departamento

\footnotetext{
109 “México tomará posesión del latifundio", El Imparcial (21 ago. 1958).

110 Telegrama de Jacinto López Moreno, 21 de agosto de 1958, AGN, Adolfo Ruiz Cortines, exp. 562.11/8.

111 “Jacinto López en la peni”, El Heraldo del Yaqui (22 ago. 1958).

112 José Abraham Mendívil fue una importante figura de la política local que se deslindó del gobierno de Álvaro Obregón Tapia. Además de ser político, fue periodista y cronista, autor de obras como Mi duelo a muerte con Vasconcelos; PAN contra PRI; Cuarenta años de política en Sonora; La democracia en Sonora y Don Ignacio Soto.

113 “Libertad a Jacinto López”, El Imparcial (24 ago. 1958).
} 
de Estado de los Estados Unidos no manifestó alarma, reacción o declaración ante la noticia de la expropiación. El diario especuló si esto se debía a que la familia Greene no había pedido ayuda o a una estricta política de no intervención. ${ }^{114}$ Lo que ocurrió a los pocos días confirmó que el gobierno estadounidense no intervino para proteger a los Greene: el procurador de Justicia del estado de Sonora giró órdenes de aprehensión contra Billy Greene. Se le acusó de falsedad de testimonio, evasión fiscal e incumplimiento familiar (este cargo quizá fue por no cumplir con sus responsabilidades hacia su exesposa). Pero no hubo arresto, Billy Greene desapareció y se rumoró que ya no estaba en la entidad. ${ }^{115}$ En pocos días pasó de ser el dueño de la propiedad más grande de Sonora a ser el hombre más buscado por la ley. Su vida privada se vio invadida, pues la prensa publicó todo tipo de noticias sobre su fracasado matrimonio.

Jacinto López seguía tras las rejas y amenazó con movilizar a los campesinos del noroeste para reclamar su libertad. ${ }^{116} \mathrm{El}$ Partido Popular y la UGOCM se unieron a las protestas, pero la justicia siguió enfocada en encontrar a Billy Greene. El procurador declaró que el perseguido estaba en la Ciudad de México, que esperaba su regreso a Sonora para arrestarlo y que realizaba gestiones para detenerlo en la capital nacional. ${ }^{117}$

\section{$\mathrm{X}$}

El Departamento de Estado no hizo reclamos por la expropiación ni se preocupó por proteger a Billy Greene. Mucho menos los funcionarios del gobierno de Arizona, quienes consultaron

\footnotetext{
114 "Se expropia latifundio", Diario del Yaqui (22 ago. 1958).

115 "Por fraude, incumplimiento familiar y falsedad, aprehenderán a W. Greene”, El Imparcial (27 ago. 1958).

116 "Concentración de masas para pedir la libertad de Jacinto", El Imparcial (29 ago. 1958).

117 “Prosigue búsqueda de Billy Greene”, El Imparcial (3 sep. 1958).
} 
con el embajador estadounidense la posibilidad de que algún miembro de la Coronado Park Comission (Comisión del Parque Coronado) se entrevistara con el presidente electo para hablar del proyecto del parque transfronterizo. Robert Hill, embajador en México, mencionó que aún no conocía bien al recién electo presidente, por lo que convendría esperar un tiempo antes de acercarse con la propuesta. ${ }^{118}$

El proyecto del Parque Coronado se creó a finales de la década de 1930. Además de ser una reserva natural, se pretendía construir un monumento de grandes magnitudes (estilo el Monte Rushmore) y un museo. Ambas atracciones tendrían como temática la historia de los pueblos prehispánicos de la región, la colonización y la cultura fronteriza. La insistencia en que se localizara en la frontera en las tierras del latifundio Greene se debía a que este fue el escenario de la expedición de Francisco Vázquez de Coronado, conquistador que exploró la región durante el siglo xvi. Se propuso que el parque fuera transfronterizo como signo de amistad entre ambos países y para rescatar la herencia hispánica de Arizona. El espacio abarcaría tierras en ambos lados de la frontera y el proyecto estipulaba que fuera administrado por una junta directiva, formada por un grupo de estadounidenses y mexicanos, ambos iguales en número. ${ }^{119}$

El Departamento de Estado prohibió al embajador Hill que organizara alguna reunión con las autoridades mexicanas para tratar el tema. Ya se le había planteado el proyecto a la presidencia y no se interesó en desarrollarlo. Segundo, una reunión para hablar del proyecto podría alentar más expropiaciones en otras partes de la frontera. Y tercero, se corría el riesgo de que

${ }_{118}$ Carta de Robert C. Hill, embajador estadounidense, 8 de septiembre de 1958, NARA, RG 84, Embassy, Mexico City, classified general records, security-segregated GR 1941-49, 1950-58, 504.13 Parks 1956/57/58.

${ }^{119}$ Carta de la Comisión Coronado al presidente Dwight D. Eisenhower, $1^{\circ}$ de septiembre de 1959, NARA, RG 84, Embassy, Mexico City, classified general records, security-segregated GR 1941-49, 1950-58 504.13 Parks 1956/57/58. 
la propuesta de cómo usar las tierras se interpretara como una intervención en la política mexicana. Para el Departamento de Estado, lo mejor era esperar el cambio de poderes y tratarlo con la siguiente presidencia. ${ }^{120}$

Uno de los políticos estadounidenses más interesados en crear el parque fue Carl Hayden. Conocido como el "Senador Silencioso", Hayden llevaba más de cuatro décadas en el Congreso como representante de Arizona; además era un experto en legislaciones referentes a reclamos de tierras. ${ }^{121}$ En septiembre de 1958, Hayden encabezó una petición en la que se le pidió al Departamento de Estado que presionara al gobierno mexicano para que accediera a la creación del Parque Coronado. La petición también iba apoyada por la presidenta de la Comisión Coronado, Grace M. Sparkes, mujer famosa por dedicar su vida a la creación de parques, el gobernador de Arizona Ernest W. McFarland (1955-1959) y organizaciones como la Cámara de Comercio de Bisbee. ${ }^{122}$

El Departamento de Estado contestó que presionar al gobierno mexicano sería un error. Le explicaron a Hayden que los pobladores de Arizona no sabían que las tierras tenían un alto peso simbólico para los sonorenses. ${ }^{123}$ Así lo constató la revista Time, que informó que para los mexicanos la expropiación había sido como si recuperaran parte del territorio perdido en 1848.

${ }^{120}$ Carta del Departamento de Estado a la embajada y al consulado en Ciudad Juárez, 22 de septiembre de 1958, NARA, RG 84, Embassy, Mexico City, classified general records, security-segregated GR 1941-49, 1950-58, 504.13 Parks 1956/57/58.

${ }^{121}$ Bacon, Encyclopedia, p. 254.

122 Carta del Departamento de Estado a la oficina del senador Carl Hyden, 24 de septiembre de 1958, NARA, RG 84, Embassy, Mexico City, classified general records, security-segregated GR 1941-49, 1950-58, 504.13 Parks 1956/57/58.

${ }^{123}$ Carta del Departamento de Estado dirigida al senador Carl Hyden, 24 de septiembre de 1958, NARA, RG 84, Embassy, Mexico City, classified general records, security-segregated GR 1941-49, 1950-58, 504.13 Parks 1956/57/58. 
Aquello no se advertía como una expropiación a un particular, sino al país vecino del norte. ${ }^{124}$

A pesar de lo expresado por el Departamento de Estado, los políticos de Arizona insistieron en reunirse con el gobierno mexicano y tratar el tema del parque. Otro senador de Arizona que apoyó el proyecto fue Barry Goldwater, político cuya carrera en ascenso culminó cuando fue candidato presidencial por el Partido Republicano en 1964 (fue derrotado por Lyndon B. Johnson). El primer día de octubre de 1958, Goldwater comunicó al embajador de su país que tenía su maleta lista para viajar a México y reunirse con el futuro presidente. Robert Hill le contestó que aún no estaba permitido negociar el tema con el gobierno mexicano, sobre todo porque los miembros de la familia Greene no recibieron remuneración alguna. En la opinión del embajador, los Greene se quedarían con las manos vacías, o en caso de ser remunerados, no sería por las administraciones de Ruiz Cortines o la de López Mateos. ${ }^{125}$ Hill insistió en que su gobierno debía mantenerse al margen, además advirtió que cada vez era menos posible que las tierras fueran usadas para el parque, pues las organizaciones campesinas intensificaron sus peticiones. ${ }^{126}$

A mediados de octubre, el senador Carl Hayden volvió a consultar la posibilidad de reunirse con el presidente electo. El Departamento de Estado le sugirió no hacerlo, pues el gobierno mexicano no manifestó su interés en usar las tierras para el parque. El proyecto del Coronado Park competía con el

124 “Mexico. Last of the latifundios", Time, 9, LXXII (sep. 1958), p. 28.

125 Álvaro Obregón Tapia constató que la remuneración a los Greene se pospuso indefinidamente por años. Al final, no hubo pago por las tierras expropiadas. Entrevista al exgobernador Álvaro Obregón Tapia, realizada por Nicolás Pineda Pablos, Hermosillo, 7 de diciembre de 1992.

${ }^{126}$ Carta Ruth Mason Hughes, primer secretario de la embajada estadounidense, dirigida a la Comisión Internacional de Parques y Bosques, $1^{\circ}$ de octubre de 1958, NARA, RG 84, Embassy, Mexico City, classified general records, security-segregated GR 1941-49, 1950-58, 504.13 Parks 1956/57/58. 
movimiento campesino en Sonora, el cual quería que se repartieran las tierras. Las autoridades en Washington insistieron al senador Hayden, y a los demás funcionarios de Arizona, que no volvieran a tocar el tema. Fue la última ocasión en la que el llamado "Senador Silencioso" intentó proponerle el proyecto al gobierno de México. ${ }^{127}$

El senador Barry Goldwater llevó sus intentos hasta las últimas instancias: viajó a México y se reunió con López Mateos en diciembre. El embajador Robert Hill tuvo autorización para organizar el encuentro, recibió a Golwater y lo llevó a la reunión con López Mateos, quien tenía tan solo dos días como presidente. ${ }^{128} \mathrm{El}$ mandatario mexiquense no sabía inglés, pero no hubo necesidad de un traductor pues el senador oriundo de Phoenix era bilingüe. Goldwater insistió en que se apoyara el proyecto del parque, principalmente con el argumento de que en Arizona había un cuarto de millón de ciudadanos mexicanos (o de ascendencia mexicana), pero muy pocos espacios públicos dedicados a la cultura hispánica. Como el mismo nombre del parque lo sugería, Coronado Park sería un espacio para rescatar la raíz hispana de Estados Unidos. López Mateos le pidió a Goldwater que continuara las pláticas con Manuel Tello, nuevo secretario de Relaciones Exteriores. ${ }^{129}$

El senador Goldwater estaba de acuerdo con la expropiación del latifundio, pues además del deseo de crear el parque,

${ }_{127}$ Carta de William B. Macomber Jr., asistente del Departamento de Estado, dirigida al senador Carl Hyden, 17 de octubre de 1958, NARA, RG 84, Embassy, Mexico City, classified general records, security-segregated GR 194149, 1950-58, 504.13 Parks 1956/57/58.

${ }^{128}$ Carta del senador Barry Goldwater, dirigida al embajador Robert C. Hill, 6 de diciembre de 1958, NARA, RG 84, Embassy, Mexico City, classified general records, security-segregated GR 1941-49, 1950-58, 504.13 Parks 1956/57/58.

${ }^{129}$ Informe de Alberto M. Vázquez, primer secretario de la embajada, 19 de diciembre de 1958, NARA, RG 84, Embassy, Mexico City, classified general records, security-segregated GR 1941-49, 1950-58, 504.13 Parks 1956/57/58. 
quizá también era uno de los políticos de Arizona en desacuerdo con el control arbitrario que los Greene tenían sobre la frontera Arizona-Sonora. Goldwater se comprometió a hablar con el gobernador Obregón Tapia y convencerlo de apoyar el proyecto. ${ }^{130} \mathrm{Al}$ final, no cuajaron los esfuerzos de este senador. Los estadounidenses desarrollaron el parque únicamente en tierras de su país, en lo que hasta el siglo Xxi se conoce como el Coronado National Memorial.

A pesar del interés del gobierno mexicano, utilizar las tierras para el parque tendría un costo político muy alto, pues los campesinos tenían muchos años reclamándolas. Usarlas para crear un parque con el gobierno de Estados Unidos sería una contradicción al discurso de que aquel pedazo de tierra volvió a ser propiedad de la nación. Años después, Carrillo Flores explicó que el gobierno mexicano se rehusó a colaborar, pues "Si considerábamos que esa tierra [la expropiada] pertenecía a México y estaba en propiedad de México, llamarla después un parque internacional podía transmitir la idea de que no habíamos conseguido plena soberanía sobre ella”. ${ }^{131}$

Los abogados de Jacinto López lograron que se le retiraran los cargos de asonada, motín y conspiración, mas no el de despojo de tierra, delito por el cual seguía preso. No se le concedió derecho a libertad bajo fianza y la prensa especuló que recibiría una condena de alrededor de cinco años. ${ }^{132}$

${ }^{130}$ Informe del senador Barry Gold water, 9 de diciembre de 1958, NARA, RG 84, Embassy, Mexico City, classified general records, security-segregated GR 1941-49, 1950-58, 504.13 Parks 1956/57/58.

${ }^{131}$ Entrevista de Joe B. Frantz con Antonio Carrillo Flores, Ciudad de México, 24 de julio de 1970 (el texto original es en inglés y la cita textual fue traducida por el autor).

132 “Resolvió el juez federal: Jacinto seguirá preso", El Imparcial (24 sep. 1958). 
Se concretaron reuniones entre los familiares de los presos con Flores Muñoz y Obregón Tapia. El primero pidió paciencia a los familiares de Jacinto López y les aconsejó no provocar el enojo del gobernador Obregón Tapia. Para sorpresa de Humberto Ochoa, concuño de Jacinto, en el momento en que Obregón Tapia dejó la sala en la que se reunieron, Flores Muñoz confesó que estaba comprometido con Lázaro Cárdenas para que los presos fueran liberados, pero que el gobernador le complicaba la labor y Ruiz Cortines no quería meter las manos en el asunto, situación que tenía a Flores Muñoz entre la espada y la pared. ${ }^{133}$ Adolfo López Mateos tomó posesión como presidente el primer día de diciembre y en menos de una semana indultó a los prisioneros. ${ }^{134}$

Tan pronto fue liberado, Jacinto López recorrió Cananea, Empalme, Cajeme, Navojoa, Los Mochis, Culiacán y Mazatlán, donde organizó a campesinos peticionarios de las tierras expropiadas. Después, el líder campesino viajó a la capital mexicana para reunirse con el presidente López Mateos y hablar del reparto del latifundio. ${ }^{135}$ Las negociaciones de Jacinto López con el nuevo presidente, así como el hecho de que éste le concediera el indulto, mantuvieron al líder campesino al margen de las invasiones efectuadas a principios de 1959. Estas invasiones se concentraron en el Valle del Yaqui y las lideró Guillermo Arce (tesorero de la UGOCM en Sonora)..$^{136}$ Los campesinos fueron desalojados violentamente por la policía municipal de Cajeme, ${ }^{137}$ municipio en el que el gobernador Obregón Tapia tenía varias propiedades.

\footnotetext{
${ }^{133}$ Moncada, Diez en el poder, p. 103.

${ }_{134}$ Moncada, Dos siglos de periodismo, p. 115.

135 Telegrama de Jacinto López Moreno dirigido a la Presidencia, 19 de diciembre de 1958, AGN, Adolfo López Mateos, exp. 549.44/7.

${ }^{136}$ Carta del comité estatal (Sonora) de la Unión General de Obreros y Campesinos de México, dirigida a la Presidencia, 1957, AGN, Adolfo Ruiz Cortines, exp. 433/303.

137 “Tropas federales y policías desalojan pepinos”, El Imparcial (7 ene. 1959).
} 
La ceremonia de reparto del latifundio Greene se fechó para inicios de febrero de 1959. ${ }^{138}$ A los días, se hizo público que la familia Greene vendió la empresa Ranchos de Cananea, una de las que tenía bajo su control (mediante una falsa arrendación) las tierras expropiadas. ${ }^{139}$ López Mateos arribó a Sonora y líderes de todo el noroeste viajaron a Cananea para asistir a la ceremonia del reparto. Con la presencia mediadora de Roberto Barrios (jefe del Departamento de Asuntos Agrarios y Colonización) y Braulio Maldonado (gobernador de Baja California), el gobernador Obregón Tapia y Jacinto López tuvieron un encuentro frente a las cámaras de los reporteros. Jacinto declaró que Obregón Tapia era su rival político, ideológico y quien lo encarceló, pero que lo respetaba y lo consideraba su amigo. ${ }^{140}$

Un suceso rompió el protocolo de la ceremonia: López Mateos le pidió al gobernador Obregón Tapia que le diera su silla al líder campesino Jacinto López, quien se encontraba entre el público ${ }^{141}$ y quien, por cierto, fue el rival electoral del gobernador Obregón Tapia en 1955 y desde entonces era uno de sus principales críticos. Aquello fue una bofetada para el hijo del expresidente Obregón. La prensa interpretó que la acción conllevaba el mensaje de que el presidente López Mateos prefería a su lado al político de oposición, líder sindical y organizador de invasiones, que al gobernador perteneciente a su partido. ${ }^{142}$ Podemos hacer otra interpretación del suceso: fue un mensaje de que López Mateos no le confiaría muchas libertades al gobernador Obregón Tapia, como quizá sí lo hizo Ruiz Cortines. Esto coincide con la actitud que el presidente mexiquense tuvo

\footnotetext{
138 “Latifundio Greene”, El Imparcial (6 ene. 1959).

139 "Ranchos de Cananea vendido a sonorenses”, El Imparcial (8 ene. 1959).

140 Antonio Rojas, "El grupo del excandidato comprende que el coco político está liquidado ya”, Diario del Yaqui (11 feb. 1959).

141 OchoA, Biografía de Jacinto López Moreno, p. 101.

${ }^{142}$ Entrevista al señor Carlos Moncada Ochoa, realizada por Miguel Ángel Grijalva Dávila, Hermosillo, 3 de marzo de 2011.
} 
ante otros liderazgos regionales, ${ }^{143}$ pues López Mateos intervino en otros conflictos del gobierno de Obregón Tapia, quien era visto por algunos como un jefe regional incapaz de resolver sus problemas. ${ }^{144}$

La ceremonia terminó cuando López Mateos y otros funcionarios repartieron los títulos de propiedad de las tierras del latifundio, dotadas con 28000 cabezas de ganado Hereford para la conformación de siete ejidos ganaderos. ${ }^{145}$ Luego de la ceremonia y el banquete, el presidente partió al aeropuerto de Hermosillo, pero invitó a Jacinto López para que viajara con él hasta la capital estatal. ${ }^{146}$

Lamentablemente para los campesinos de la UGOCM, su organización no fue beneficiada en el reparto. La Secretaría de Agricultura, entonces bajo la dirección de Julián Rodríguez Adame, tomó como lista oficial de peticionarios la que presentó la Confederación Nacional Campesina (CNC), afiliada al PRI. Los miembros de la CNC salieron beneficiados a expensas del sacrificio de los miembros de la UGOCM, quienes fueron los que reclamaron la expropiación, invadieron las tierras y vivieron a la intemperie. ${ }^{147}$ La relación entre Jacinto López y Adolfo López Mateos comenzó a deteriorarse a partir de aquello. Se distanciaron más durante el conflicto ferrocarrilero, pues luego de que el régimen aprisionó a Demetrio Vallejo, Jacinto López lo visitó en prisión y después se reunió con López Mateos para pedirle

143 Alisky, “The governors of Mexico", p. 15.

${ }^{144}$ La Presidencia dejó de ratificar a Margarito Ramírez como gobernador de Quintana Roo (Careaga, Quintana Roo, pp. 230-231). A Gonzalo N. Santos (Kennedy, The Middle Beat, p. 55) y a Leobardo Reynoso, Flores (Zacatecas, p. 205) se les ofrecieron cargos que implicaban apartarlos de su región. A Obregón Tapia no le pidieron su renuncia ni se le apartó de Sonora, pero se le negó mucho apoyo político en las consecuentes crisis que sacudieron a su gobierno.

${ }_{145}$ Almada, Breve historia de Sonora, pp. 152.

146 “Adolfo López Mateos en Cananea”, El Imparcial (9 feb. 1959).

147 Sanderson, Agrarian Populism, p. 157. 
la libertad del líder ferrocarrilero. Aquella reunión terminó en una fuerte discusión. ${ }^{148}$

A pesar del distanciamiento, López Mateos no cambió su opinión positiva sobre Jacinto López. Así lo confirmó Humberto Romero, secretario de la Presidencia, quien relató que en una ocasión López Mateos expresó que veía en Jacinto a un líder honesto, valiente y de patriotismo a toda prueba. ${ }^{149} \mathrm{La}$ influencia de Jacinto López, la de otros líderes sonorenses de oposición y la complicada relación con Obregón Tapia, motivaron a que López Mateos le negara su apoyo al gobernador sonorense en los últimos tres años de su administración.

\section{XII}

Una conclusión que podemos obtener de las expropiaciones de 1958 en el noroeste mexicano, es que fueron un cumplimiento parcial de las demandas. Las expropiaciones que realizó el gobierno de Ruiz Cortines en Sinaloa, Baja California y finalmente Sonora, fueron una muestra y un aviso de lo que se aproximaba en la administración de Adolfo López Mateos. A partir de entonces el gobierno federal inició una táctica para disminuir el descontento en el campo al incrementar los repartos agrarios.

El sexenio de Adolfo López Mateos repartió más tierras que cualquiera de sus tres predecesores (Ruiz Cortines, Alemán Valdés y Ávila Camacho). Estos repartos fueron una respuesta al descontento en el campo, un intento por conseguir mayor estabilidad política y evitar posibles rebeliones campesinas, fenómeno que se presentaba en varios países de Latinoamérica. Algunos grupos campesinos vieron en esa política un eco del sexenio cardenista y, ante el aparente crecimiento de repartos y la promesa de más en el futuro, apaciguaron sus reclamos y sus

\footnotetext{
${ }_{148}$ Ochon, Biografía de Jacinto López Moreno, p. 103.

149 Oсно, Biografía de Jacinto López Moreno, p. 104.
} 
tácticas, como las invasiones. En el caso del noroeste mexicano, y particularmente en el de Sonora, la Unión General de Obreros y Campesinos de México (UGOCM), organización campesina de mayor influencia en esos años, cooperó con el gobierno de López Mateos y le dio un voto de confianza.

La expropiación y reparto del latifundio Greene fue quizá la más complicada de las realizadas ese año. Tanto en Sinaloa como en Baja California, los gobiernos locales cooperaron con los peticionarios y el resultado fueron invasiones campesinas que terminaron con prontitud. En cambio, en Sonora, el caso del latifundio Greene se complicó en mayor medida por la negativa del gobierno local a cooperar con los peticionarios. A pesar de la mala condición legal de las tierras, los Greene se encontraban aparentemente protegidos por el gobierno estatal y la ayuda de personajes influyentes como el expresidente Emilio Portes Gil. Tuvo que presentarse una combinación de factores para que se realizara la expropiación: 1) el activismo de la UGOCM; 2) las declaraciones y pruebas presentadas por Rosina Cavazos de Greene; 3) el revuelo del tema en la prensa, y 4) la abierta actitud, incluso deseosa, de una parte del gobierno de Estados Unidos para que se realizara la expropiación.

Por último, si la expropiación de las tierras dio una muestra de la política venidera en esta materia, el reparto también dio una muestra de la actitud que tomaría el gobierno ante los disidentes. La adquisición del latifundio Greene fue un logro celebrado por todos, pero el reparto de las tierras sólo fue celebrado por los pertenecientes al sistema, pues los principales beneficiarios fueron los afiliados de la Confederación Nacional Campesina (CNC). Los que se sacrificaron en la lucha por la tierra, es decir, los miembros de la UGOCM, quedaron excluidos y con ello recibieron el mensaje de que el régimen seguiría negándoles beneficios. Aunque los campesinos disidentes tenían la misma postura que el gobierno, aquella alianza no fue suficiente para que el régimen dejara de excluirlos. 


\section{SIGLAS Y REFERENCIAS}

AGN Archivo General de la Nación, Ciudad de México.

NARA National Archives and Records Administration, Estados Unidos de América.

Alisky, Marvin, “The governors of Mexico”, en Soutbwestern Studies, 3: 4 (1965), pp. 1-31.

Almada Bay, Ignacio, Breve historia de Sonora, México, Fondo de Cultura Económica, El Colegio de Sonora, 2011.

Baca Calderón, Esteban, Juicio sobre la guerra del Yaqui y génesis de la buelga de Cananea, Hermosillo, Contrapunto 14, 1997.

Bacon, Donald C. (ed.), The Encyclopedia of the United States Congress, Nueva York, Simon and Schuster, 1995.

Bantjes, Adrian A., As if Jesus Walked on Earth: Cardenismo, Sonora, and the Mexican Revolution, Wilmington, SR Books, 1998.

Cárdenas García, Nicolás, “La huelga de Cananea en 1906. Una reinterpretación”, en Estudios Sociológicos, XVI: 46 (1998), pp. 117-146.

Careaga Viliesid, Lorena, Quintana Roo. Una historia compartida, México, Instituto de Investigaciones Dr. José María Luis Mora, 1990.

Camou Healy, Ernesto, Rocío Guadarrama, José Carlos Ramírez (coord.), Historia general de Sonora, t. V, Historia contemporánea de Sonora 1929-1984, Hermosillo, Gobierno del estado de Sonora, 1985.

Cid Capetillo, Ileana, “Francis White (1953-1957)”, en Suárez Argüello (coord.), 1998, pp. 298-305.

Encinas Johnson, Luis, Progreso y problemas de México, México, Stylo, 1954.

Flores Olague, Jesús, Zacatecas. Historia breve, México, Fondo de Cultura Económica, El Colegio de México, Fideicomiso Historia de las Américas, 2011.

Gracida Romo, Juan José, El Sonora moderno (1892-1910), en RADDING DE MurrietA, 1985, pp. 77-136.

Grijalva Dávila, Miguel Ángel, “Jacinto López Moreno. Biografía de un agrarista sonorense”, tesis de maestría en Ciencias Sociales, Hermosillo, El Colegio de Sonora, 2012.

Hernández Rodríguez, Rogelio, Presidencialismo y hombres fuertes en México. La sucesión presidencial de 1958, México, El Colegio de México, 2015. 
Kennedy, Paul P., The Middle Beat. A correspondent's View of Mexico, Guatemala and El Salvador, Nueva York, Columbia University, 1971.

Leñero, Vicente, Asesinato. El doble crimen de los Flores Muñoz, México, Plaza y Janés, 1997.

López Gutiérrez, Ángel, Encuentro con mi destino. Apuntes sobre Sonora y de mi relación con los Sres. ExGobernadores, Don Rodolfo Elías Calles, Lic. Luis Encinas Johnson y Don Faustino Félix Serna, Hermosillo, s. e., 1999.

Lozano R., Erasmo, Remembranzas, críticas y opiniones, Cananea, s. e., 1991.

Marks III, Frederick W., Power and Peace. The Diplomacy of John Foster Dulles, Westport, Praeger Publishers, 1993.

Mendívil Rincón, José Abraham, Cuarenta años de política en Sonora, Hermosillo, Imprenta Económica, 1965.

Mendívil Rincón, José Abraham, Don Ignacio Soto, Hermosillo, Impresora del Noroeste, 1972.

Mendívil Rincón, José Abraham, La democracia en Sonora, Hermosillo, Publicidad Mendívil, 1980.

Mendívil Rincón, José Abraham, Mi duelo a muerte con Vasconcelos, Hermosillo, Publicidad Mendívil, 1999.

Mendívil Rincón, José Abraham, PAN contra PRI, Hermosillo, Imprenta del Noroeste, 1976.

Moncada Ochoa, Carlos, Cincuenta años en esto, Hermosillo, El Sembrador, 2003.

Moncada Ochoa, Carlos, Diez en el poder: la política en Sonora vista a través de sus últimos diez gobernadores (1943-1997), México, Edamex, 1997.

Moncada Ochoa, Carlos, Dos siglos de periodismo en Sonora, Hermosillo, Ediciones EM, 2000.

Moncada Ochoa, Carlos, La sucesión politica en Sonora, 1917-1985, Hermosillo, Latinoamericana, 1988.

Ochoa Bustamante, Humberto, Biografía de Jacinto López Moreno, Hermosillo, Editora Nacional, 1991.

Olais Olivas, Alejandro, Sonora reta al sistema, Obregón, s. e., 1984.

Peña Sierra, Elsa y José Trinidad Chávez Ortiz, “Ganadería y agricultura en la Sierra, 1929-1980”, en Camou Healy et al. (coord.), 1985, pp. 265-281. 
Radding de Murrieta, Cynthia (coord.), Historia General de Sonora, t. IV, Sonora Moderno: 1880-1929, Hermosillo, Gobierno del Estado de Sonora, 1985.

Ramírez, José C., Rocío Guadarrama, Óscar Conde, Ricardo León, Cristina MARTínez, Lourdes Martínez, "Los resultados de la modernización en el campo", en Camou Healy, Guadarrama, Ramírez (coords.), 1985, pp. 175-191.

Sanderson, Steven E., Agrarian Populism and the Mexican State. The Struggle for Land in Sonora, Berkeley, Calif., University of California, 1981.

SuÁrez Argüello, Ana Rosa (coord.), En el nombre del Destino Manifiesto. Guía de ministros y embajadores de Estados Unidos en México 1825-1993, México, Secretaría de Relaciones Exteriores, Instituto de Investigaciones Dr. José María Luis Mora, 1998.

Turner, John Kenneth, México bárbaro, México, Quinto Sol, 1985. 